Published in final edited form as:

Rheum Dis Clin North Am. 2012 August ; 38(3): 441-476. doi:10.1016/j.rdc.2012.09.003.

\title{
Epidemiology of Spondyloarthritis
}

\author{
Carmen Stolwijk, MD,
}

Department of Medicine, division of Rheumatology, Maastricht University Medical Center, PO

Box: 5800, 6202 AZ Maastricht, The Netherlands, Tel: + 3143 3884292, Fax: +31 433875006

\section{Annelies Boonen, MD, PhD [Associate Professor of Rheumatology], \\ Department of Medicine, division of Rheumatology, Maastricht University Medical Center, PO Box: 5800, 6202 AZ Maastricht, The Netherlands, Tel: + 3143387 7382, Fax: +31 433875006 , Maastricht, the Netherlands}

\author{
Astrid van Tubergen, MD, PhD [Rheumatologist], and \\ Department of Medicine, division of Rheumatology, Maastricht University Medical Center, PO \\ Box: 5800, 6202 AZ Maastricht, The Netherlands, Tel: + 31 43, Fax: +31 433875006
}

\section{John D. Reveille, M.D. [Professor and Director]}

Division of Rheumatology and Clinical Immunogenetics, Department of Medicine, MSB 5.270, The University of Texas Health Science Center at Houston, 6431 Fannin, Houston, TX, 77030, Tel: 713-500-6900, Fax: 713-500-0580 Carmen Stolwijk: c.stolwijk@maastrichtuniversity.nl; Annelies Boonen: a.boonen@mumc.nl; Astrid van Tubergen:
a.van.tubergen@mumc.nl; John D. Reveille: john.d.reveille@uth.tmc.edu

\section{Synopsis}

Spondyloarthritis $(\mathrm{SpA})$ represents a group of interrelated diseases with common clinical features and a close association with HLA-B27. Figures on the incidence and prevalence of diseases vary highly dependent on methodological differences between studies, the case definition used to classify disease and on the prevalence of HLA-B27 in the population studied. When summarizing the available literature, incidence rates of SpA are mainly based on the ESSG criteria and range between 0.48 and 63/100.000 while prevalence rates vary between 0.01 and $2.5 \%$. For ankylosing spondylitis (AS), the most widely recognized representative of the SpA group of diseases, incidence rates of 0.44-7.3/100.000 and prevalence rates of 0.007-1.7\% have been described in studies that were based on the (modified) New York criteria to classify cases. The incidence of psoriatic arthritis (PsA) varied from 3.6 up to 23.1/100.000 in different studies and prevalence between $<0.1 \%$ and $0.4 \%$, using a variety of classification criteria. The incidence of $\operatorname{ReA}$ has been estimated between 0.6 up to 28/100.000 in studies based on different source populations and different case definitions. The newly proposed criteria for axial SpA and peripheral SpA present an attractive new approach to facilitate classification of the SpA into two main subtypes and the

(C2012 Elsevier Inc. All rights reserved.

Correspondence to: Annelies Boonen, a . boonen@mumc. nl.

Publisher's Disclaimer: This is a PDF file of an unedited manuscript that has been accepted for publication. As a service to our customers we are providing this early version of the manuscript. The manuscript will undergo copyediting, typesetting, and review of the resulting proof before it is published in its final citable form. Please note that during the production process errors may be discovered which could affect the content, and all legal disclaimers that apply to the journal pertain. 
axial SpA criteria allow earlier detection of patents with inflammatory back pain. It should be emphasized that these criteria were developed for use in a (specialized) clinical setting and not for large epidemiological studies.

\section{Keywords}

Spondyloarthritis; Ankylosing Spondylitis; Psoriatic arthritis; Reactive arthritis; Epidemiology; Incidence; Prevalence

\section{Introduction}

The term spondyloarthritis $(\mathrm{SpA})$ refers to a disease (i.e for which criteria have been developed) but also to a concept that represents a group of interrelated disorders. Classically these disorders comprise ankylosing spondylitis (AS), psoriatic arthritis (PsA), reactive arthritis (ReA), SpA related to inflammatory bowel disease (IBD-SpA) and undifferentiated SpA (uSpA). More recently a classification into an axial and peripheral disease has been proposed. Phenotypically, these diseases have several features in common including inflammatory back pain, peripheral arthritis (usually an oligoarthritis of the lower limbs), enthesitis, dactylitis, and extra-articular features such as uveitis, psoriasis and IBD. Genetically, the diseases are associated with the major histocompatibility complex class 1 antigen HLA-B27.

Epidemiology is the study of the distribution and the determinants of diseases in human populations. The epidemiology of a disease is the most important determinant of the burden of a disease in a population. This chapter will focus on the epidemiology of SpA all over the world by reviewing the literature on incidence and prevalence of the entire SpA group as well as the specific disorders belonging to SpA. However, it is important to consider first some challenges when determining the epidemiology of a disease. Firstly, the frequency of diseases reported in studies depends on criteria used for confirmation of the presence of a disease in the individual patients. For this purpose, classification criteria have been developed, and depending on the purpose and the methodological approach, they can have different test-characteristics. Secondly, numbers on prevalence and incidence may vary due to differences in study design, including the target population, sampling method and approach to assess the disease criteria. Therefore, these two aspects will be discussed first in the next paragraphs.

\section{Importance of classification criteria and design for epidemiological studies} Classification criteria and their use in large epidemiological studies

In order to reliably estimate the prevalence of a disease, criteria are needed to identify homogenous groups of patients. In the last 50 years, major advances have been made in the recognition and classification of SpA as an entity and the specific disorders belonging to SpA. However, criteria developed for classification might not be useful for conducting epidemiological studies in the population but might be specifically designed for identification of patients attending specialized clinics and for inclusion in trials or observational studies. Classification criteria, in contrast to diagnostic criteria, are designed 
for high specificity to avoid misclassification. As a result, they lack sensitivity at early or mild stages of disease, which might be a drawback in epidemiological studies, due to a possible underestimation of the incidence or prevalence of the disease and for diseases which are not frequent, large samples are needed to provide reliable estimates on incidence and prevalence. Secondly, classification criteria might include items, such as technical procedures (for instance, MRI), which might not be feasible for application in large population studies or items that require a specific physician diagnosis (for example, the presence of psoriasis).

Before classification criteria can be developed at all, disease have to be recognized as a 'morbus sui generis' by physicians. It was mainly in the $19^{\text {th }}$ and beginning of the $20^{\text {th }}$ century that that physicians raised the idea of SpA as a distinct disease. In the midnineteenth century, several cases of psoriasis in association with arthritis were published by Rayner, Cazenave, Devergre and Gilbert [1]. The name 'psoriasis arthritique' was first introduced in 1860 by skin physician Pierre Bazin. In the same century, the first cases of patients with inflammatory back pain and limited mobility of the spine (or ankylosis in postmortem studies) were reported by Travers (1824) and Brody (1850) and later by Vladimir Bechterev (1893), Adolf Strümpel (1897) and Pierre Marie (1898). Several names were proposed to distinguish this disease from rheumatoid arthritis, yet the term 'rheumatoid spondylitis' was used for many years and only much later the term AS became widely accepted. In 1916, Hans Reiter contributed to the identification of the disease ReA for patients with arthritis, urethritis and conjunctivitis, although already in 1507 a patient was reported with arthritis in association with urethritis. Later in the $20^{\text {th }}$ century, the association between ulcerative colitis and arthritis was first recognized (1930) and, in 1938, a patient with Crohn's disease was described who developed polyarthritis [1]. The ability to apply the RF-test more widely in the 1950s (after its discovery by Waaler and Rose in 1940 and 1948 respectively), helped to confirm that the entire group of disease described above were distinct from rheumatoid arthritis because they lacked rheumatoid factor and therefore the term 'seronegative variants of rheumatoid arthritis' was introduced. During the 1960s, Moll and Wright observed in family studies the striking association between sacroiliitis/AS and several other disorders such as PsA, ulcerative colitis, and arthritis related to Crohn's disease. In 1974, Moll and Wright established the concept of these disorders and chose as collective name the term 'spondarthritides' [2]. Remarkably, their observation was done without consideration of the HLA-B27 associations (which had only been described the preceding year) but resulted from clinical and radiological findings. The consideration of HLA-B27 in AS and other diseases in SpA, commencing during the 1970s, provided further confirmation of the concept [3].

Once the diseases were well established in clinical rheumatology, the need for classification criteria was recognized in order to be able to create homogenous groups of patients for clinical or population studies. Table 1 represents a chronological overview of the main criteria proposed and used in either clinical or epidemiological studies, with a brief description of the specific aim, methodological approach and description of items within the criteria that might hamper applicability in large epidemiological studies. In 1961, criteria were proposed to identify patients with AS for population surveys (Rome criteria) [4]. They required either the presence of four out of five clinical criteria or a sixth criterion 
(radiographic sacroiliitis) plus one of the clinical criteria. The Rome criteria were based on expert opinion, but when evaluated later in a population study among American indigenous groups, the role of the radiographs was not found to be satisfactory [5]. This led to the revision of the Rome criteria into the New York criteria [6]. In New York, an expert committee agreed that for epidemiological purposes the diagnosis of AS should not be made without X-ray evidence of sacroiliitis, and therefore the presence of sacroiliitis was required for fulfillment of the criteria. Further, the clinical items were revised in an attempt to make them more objective. In an evaluation of the New York criteria, Moll and Wright found that the clinical criteria failed in terms of sensitivity and specificity [7]. Therefore, a modification was proposed in 1984, the modified New York criteria (mNY), in which an item for inflammatory back pain was added, but the radiographic criterion was kept [8]. Since then, the mNY criteria have been the most widely applied criteria in both clinical and epidemiological studies in AS. The main restriction of these criteria for use in epidemiological studies is that, although they perform well in established disease, they lack sensitivity in the early disease stage, in which radiographic damage is not yet visible, which could cause a delay up to 6-8 years in diagnosis [9].

For PsA, the first classification criteria were proposed in 1973 by Moll and Wright and required inflammatory arthritis, presence of psoriasis, and absence of rheumatoid factor [10]. These criteria discriminated poorly between psoriatic and rheumatoid arthritis. More sensitive criteria for clinical studies were proposed by Vasey and Espinoza, by McGonagle et al, and by Gladman, but none of them have been widely adopted nor validated at a satisfactory level [11]. Therefore, the ClASsification of Psoriatic Arthritis (CASPAR) criteria were developed in 2006 by the GRAPPA group [12]. The CASPAR criteria are easy to use and likely to perform well, although classifying early disease is the most important limitation of the criteria. Further, the sensitivity of the CASPAR criteria for use in epidemiological studies is not clear.

For ReA, despite several attempts, no universal validated classification or diagnostic criteria are available. Based on discussions at the $4^{\text {th }}$ International Workshop on Reactive Arthritis in 1999, a consensus was achieved that the term ReA should be confined to patients, who present with clinical features typical of ReA, and in whom the preceding infection is caused by a microbe, which is commonly associated with ReA [13]. Further, preliminary, classification criteria for ReA were proposed but have never been validated. On the same line, no formal classification criteria for IBD-SpA or uSpA have been developed to our knowledge.

It was recognized that there also was a need for criteria to classify the whole spectrum of $\mathrm{SpA}$, comprising the specified as well as unspecified forms of the disease. For this purpose, the European Spondyloarthropathy Study Group (ESSG) and Amor criteria were developed in the early 1990s $[14,15]$. They both cover the whole spectrum of SpA and include at the same time the axial and peripheral manifestations but also give weight to other features of the SpA concept not related to spinal or articular symptoms. The ESSG-criteria are easy to apply and therefore often used in epidemiological studies. However, it has been shown that these criteria sets lack sensitivity and specificity $[16,17]$. Considering these drawbacks, efforts have been made in the last years to standardize and improve the making of an early 
diagnosis, and new classification criteria have been established by the Assessment of SpondyloArthritis International Society (ASAS) $[18,19]$. According to these new ASAS classification criteria, $\mathrm{SpA}$ is divided into predominantly axial involvement and predominantly peripheral manifestations. According to the ASAS axial SpA criteria, a patient suffering from chronic back pain with age at onset before 45 years can be classified as having axial SpA if sacroiliitis on imaging (radiographs or MRI) is present plus at least one SpA feature, or, in the absence of sacroiliitis on imaging, if HLA-B27 is positive plus at least two other SpA features. A patient can be classified as having peripheral SpA, if peripheral arthritis, enthesitis or dactylitis is present, plus at least one or two other SpA features. The advantage of the ASAS axial SpA criteria is the inclusion of MRI, which is able to show inflammation of the sacroiliac joints in an early stage of disease. The ASAS axial SpA criteria have shown to perform well, also in early stages of disease [19]. However, the inclusion of MRI and HLA-B27 testing make them infeasible for use in large epidemiologic studies. Power requirements to determine the prevalence of an uncommon disease hamper the application in large studies when MRI would be needed in a large proportion of patients. Not only are such exams expensive, but classification of abnormalities on MRI should have sufficient specificity to avoid overdiagnosis. However, also including plain X-rays in large population studies is a challenge, not in the least because ethical committees would raise objections against radiographs in healthy subjects.

Having elaborated on classification-criteria, we acknowledged that the ASAS criteria cannot simply be applied in large epidemiological (population) studies. Several alternative approaches can be seen in the literature. A two stage approach can be used, in which subjects are pre-screened by questionnaires and are invited for further exams in case of suspicion based on the (sensitive) screening question. In addition, other criteria such as ICD codes, insurance claims, or patients' reported physician made diagnoses have been used in epidemiological studies. All these alternative choices make assumptions with regard to accuracy of the diagnosis but none of them are accurate against true evaluation by classification criteria.

\section{Quality of study design for prevalence and incidence studies}

Decisions in policy and health care utilization are often influenced by prevalence and incidence of chronic diseases [20]. Therefore, studies on prevalence and incidence should be unbiased, high quality studies. However, these studies are always observational and this evidence is generally considered as low. Two sets of guidelines can be recognized when considering quality of (observational) studies. Firstly, guidelines can define how to conduct a study to the highest possible standards. For example, the initiative named Strengthening the Reporting of Observational Studies in Epidemiology (STROBE) developed a checklist of 22 items, with recommendations about what should be included in a more accurate and complete description of observational studies [21]. Secondly, guidelines may define how to assess the risk of bias of individual studies when aggregating them in a systematic review. This is important, since a study may be performed to the highest possible standards, yet still has a high risk of bias. In 2006, Croft reported that the assessment of the quality or risk of bias of reviews on observational studies was rarely done and often incomplete because of lack of instruments and guidance, in particular for studies on incidence and prevalence (22). 
Since then, much effort has been done to improve this shortcoming. Sanderson identified in a review 86 approaches to assess risk of bias in observational studies and concluded there was a need for more reliable tools (23). Shamlian et al reviewed tools to assess the quality and/or risk of bias of prevalence and incidence studies and reported the absence of agreement on type of items and way to score items, likely reflecting the need for extensive adaptations depending on the specific disease and population of interest (refer). In the same paper, they present a new checklist to assess the methodological and reporting quality of observational studies of incidence and prevalence that was mainly based on the review of existing instruments and expert knowledge (Delphi) [24]. Two aspects can be distinguished: (1) external validity, which is defined as the extent to which the results of a study can be generalized to the target population, and (2) internal validity, which is the extent to which the results of a study are correct for the subjects. When testing the tool, interrater agreement was poor and the authors recommended further testing of checklists. Recently, Hoy et al. developed another tool for risk of bias of prevalence studies [25]. This tool makes a distinction between assessing whether the research was conducted to the highest possible standards (methodological quality) and to which the results can be believed (risk of bias). The items in this risk of bias tool include the following questions (a 'yes'-answer implicating a low risk of bias and a 'no'-answer a high risk of bias):

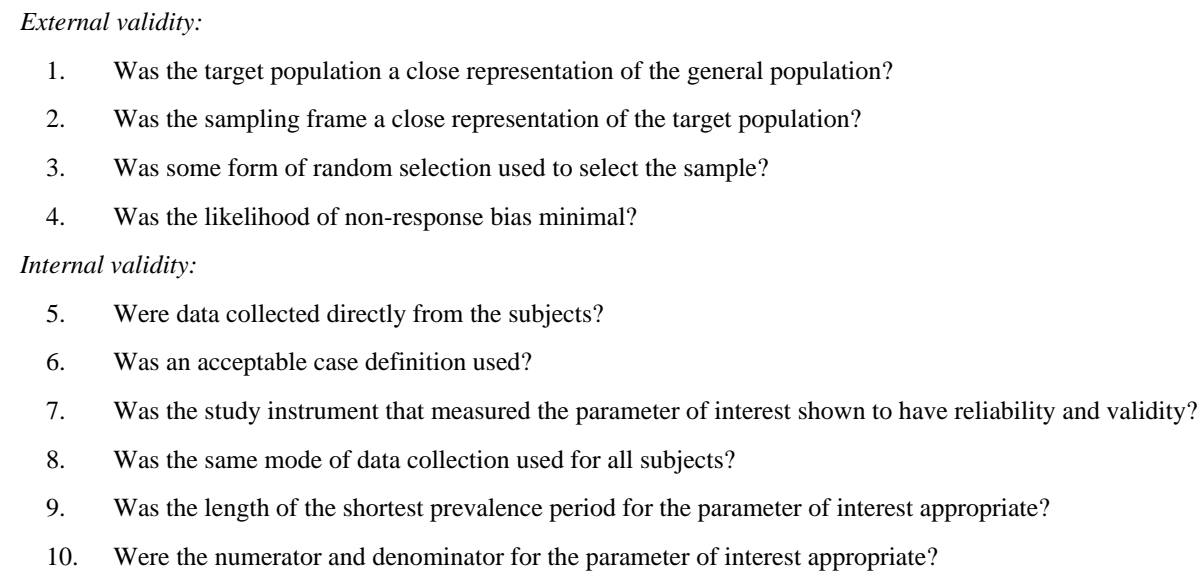

When interpreting studies on incidence and prevalence of SpA, these important questions were considered in the present review.

\section{Literature review on prevalence and incidence SpA}

\section{Search strategy and appraisal}

To be able to present a clear picture on the epidemiology of the SpA, an electronic search of PubMed was performed up to July 2012 using the following search terms: "spondyloarthritis", "spondyloarthropathy", "ankylosing spondylitis", "psoriatic arthritis", "reactive arthritis", undifferentiated spondyloarthritis", "incidence", "prevalence", and "epidemiology". We limited our search to original articles and reviews published in English. Further, the reference lists of articles identified by the search strategy were searched. The search and selection of articles was done by one person mostly. Since this report did not have the intention to be a systematic review, no formal assessment or risk of bias was 
performed but along the data extraction the main items for external and internal validity were checked and included in the tables (see tables 2-9).

\section{Distribution HLA-B27 worldwide}

It is well known that the prevalence of SpA and SpA related diseases show considerable differences among ethnic groups and populations Partly this can be explained by differences in the prevalence of HLA-B27, with which the prevalence of SpA, and in particular AS, is roughly related. However, it should be noted there are very few studies on HLA-B27 prevalence that are truly population based or nationally representative. The prevalence of HLA-B27 is highest in the Pawaia tribe in Papua New Guinea (53\%) [26], the Haida indigenous Americans on the Queen Charlotte Islands in Western Canada (50\%) [27] and Chukotka Eskimos in Eastern Russia (40\%)[28]. In Northern Scandinavian countries, HLAB27 positivity is also reported to be common (15-25\%) [29-31]. In the Western European population, the prevalence of HLA-B27 is estimated 4-13\%, whereas HLA-B27 positivity is uncommon in the Arab countries (2-5\%) [32] and Japan (1\%) [33].

Overall, most patients with AS possess HLA-B27. Approximately $90 \%$ of the patients with AS of Germanic and northern European extraction are HLA-B27 positive. However, there are some racial differences. AS is virtually absent among South-American Indians, Australian Aborigines and African blacks [34]. Among blacks, the B27-negative AS forms a much greater proportion of AS patients $(<60 \%)$ [35], probably because of the increased significance of non-B27 alleles. Also in the Middle East, the strength of the association is relatively weak compared with Western countries (25-75\%) [36-38] and in sub-Saharan Africa the prevalence of HLA-B27 in patients with AS is reported to very low. This was indirectly confirmed in a US multi-racial/ethnic study. National Health and Nutrition Examination Survey (NHANES)-2009 was the first nationally representative and population based prevalence of HLA-B27 in the US (6.1\%), that was appropriately powered for whites (7.5\%) and Mexican Americans (4.6\%) but lacked power to guarantee the accuracy of the $1.1 \%$ frequency observed in African Americans [39]. The relation of HLA-B27 with other SpA subtypes is weaker compared to AS and is reported to be up to $70 \%$ in patients with ReA; $60-70 \%$ of patients with axial PsA; $25 \%$ of patients with peripheral PsA and up to $70 \%$ in patients with IBD-SpA [40, 41]. Different subtypes of HLA-B27 can be found throughout the world with different strengths of association with AS. HLA-B*2705 and $B * 2702$ are the primary subtypes in Caucasians, $B * 2704$ and $B * 2705$ in Eastern Asia and $B * 2708$ in Southern Asia [40]. Other subtypes $(B * 2706$ and $B * 2709)$ were thought to be protective for the disease, although with both subtypes, AS cases have now been reported [41].

\section{Incidence and prevalence of spondyloarthritis}

Incidence-Only 4 studies reported the incidence of SpA as a disease entity which varied from 0.48 in Japan to 62.5/100.000 in Spain (Table 2). The low prevalence in Japan coincides with a very low prevalence of HLA-B27 $(<0.5 \%)$. The study was based on a nationwide questionnaire survey in which physicians of institutes with possible SpA patients were asked to review the medical records [33]. SpA was classified based on clinical and radiographic features. The incidence was determined with the assumption that at least one- 
tenth of the SpA population was recruited by the survey and was estimated not to exceed 0.48/100.000 person-years. The two most prevalent SpA subtypes were AS (68.3\% of SpA) and PsA (12.7\% of SpA). In a study from Finland, based on referrals to rheumatology outpatient clinics, the annual incidence of SpA was 52/100.000 person years [42], with PsA as most prevalent subtype (44.4\%), followed by uSpA (25\%). Another study from Finland, which used records of a nationwide insurance program, estimated an overall incidence of SpA of 19/100.000. This study only included patients who needed medical treatment for their condition [43]. Also in this study, PsA was the most frequent subtype (37\%), followed by AS (32\%).

In the last years, the importance of an early diagnosis of $\mathrm{SpA}$ has become clear and efforts have been made to diagnosis patients in an early stage. In a study from Spain, general practitioners in Madrid were asked and trained to refer all patients under 45 years with either inflammatory back pain or asymmetric arthritis of lower limbs with 3-24 months symptom duration to a specialized early arthritis clinic during 6 consecutive months [44]. Case definition was based on the ESSG criteria. The annual estimated incidence of SpA was $62.5 / 100.000$, suggesting a high incidence of early SpA. However, ESSG criteria were used as gold standard, although it has been described that only $50 \%$ of the patients who fulfill the ESSG criteria are still classified as SpA five years later [16].

Prevalence-Sixteen studies reported data on the prevalence of SpA, which varied from $0.01 \%$ in Japan to $2.5 \%$ in Alaska (Table 3). The highest prevalence of $2.5 \%$ in Alaskan Eskimos was based on combined ESSG and Amor criteria [45, 46]. However, most studies on prevalence of $\mathrm{SpA}$ are conducted in Europe. In a study from France prevalence of SpA was estimated to be $0.30 \%$ [47]. The study was based on a telephone survey in which a random sample of telephone numbers was selected and patients were asked if a diagnosis of SpA was ever made. Only patients with suspected SpA were called by a rheumatologist. This method probably underestimated the prevalence of SpA since only patients with a diagnosis were captured. Another telephone survey population study from France revealed a prevalence of $0.47 \%$, which was nearly similar to the prevalence of rheumatoid arthritis in the same survey [48]. A study from Lithuania, using the same methodology as the study from France, estimated a SpA prevalence of $0.84 \%$ [49]. As indicated, not only the sensitivity of the initial screening question, but also possible bias in persons having or having not a telephone (possibly disfavouring persons of lower socio-economic status) should be taken into account when interpreting the figures. In a German study, 348 blood donors of which half were HLA-B27 positive were screened for SpA using the ESSG criteria and included the use of MRI for diagnosing early AS [50]. The estimated prevalence of SpA among the adult population was estimated at $1.9 \%$, although this number was later adjusted to $1.73 \%$ (to adjust for selection bias when generalizing blood donors to the general populaton) [51]. However, it is doubtful if blood donors are a truly representative sample of the general population. In a Turkish population study 145 out of 2887 subjects who responded positively on a questionnaire were evaluated by a rheumatologist and showed a prevalence of $1.05 \%$ according to the ESSG criteria [50]. A comparable prevalence of SpA was reported in a study in central Italy (1.1\%), despite the low HLA-B27 prevalence in Italy [51]. In this study, the most common form of SpA was PsA (38\%) followed by AS (34\%). A 
population study in persons older than 50 years of age from the Azores, Portugal, estimated the overall prevalence of SpA according to the ESSG criteria at 1.6\%, and remarkably only one in seven patients had a previous diagnosis of SpA [52]. In a population based epidemiological study in Greece, the estimated prevalence of SpA was $0.49 \%$ [55].

Recently, a prevalence study of SpA has been conducted in the USA. Both, ESSG (using 4 of 7 items) and Amor criteria (using 6 of 11 items) had been assessed in a representative sample of 5013 US adults aged 20-69 years along the 2009-2010 US National Health and Nutrition Examination Survey (NHANES). The overall age adjusted prevalence of SpA using the Amor criteria was $0.9 \%$ and when using the ESSG criteria 1.4\% [56]. It should be noted that not all items required for the ESSG and Amor criteria could be assessed as it concerned a self-report questionnaire excluding items based on spinal mobility, laboratory assessment or radiography.

In most parts of Asia, the prevalence of SpA tends to be lower than in other countries in the world. A recent review from China estimated the prevalence between 0.49-0.93\% [57]. However, a remarkably lower prevalence of SpA of $0.0095 \%$ was reported in the study from Japan [31]. In Thailand and Vietnam prevalences were estimated of $0.12 \%$ and $0.28 \%$ resp. $[58,59]$. In the Middle-East, the prevalence of SpA is relatively low. A study from Iran estimated a prevalence of $0.23 \%$ and in Pakistan of $0.1 \%$. It should be noted that the studies from China, Thailand, Vietnam, Iran and Pakistan were Community-Oriented Program for the Control of rheumatic disease (COPCORD) studies, which is a program to estimate the burden of pain, arthritis and disability in the community with the aim to improve musculoskeletal health. Providing accurate prevalence information is not the main focus of the program.

The limited number of studies that performed further subtyping suggested invariably that within patients with $\mathrm{SpA}$ a large proportion have undifferentiated $\mathrm{SpA}$, a disease entity that cannot be classified further into AS, PsA or ReA. [46,48,50]

Phenotypic variations within SpA-Table 3 shows that data on gender diversity in the occurrence of SpA are conflicting. A recent English study in patients with SpA showed that female disease likewise was at least as severe as male disease [80]. In the same study, a slightly different phenotype was among sexes found. Women predominantly suffered from upper axial disease, together with stiffness, fatigue, and enthesitis. In contrast, men predominantly suffered from peripheral joint disease, whereas back pain was equally frequent in both sexes [80]. A study from Brazil found that female gender was more frequently associated with peripheral $\mathrm{SpA}$, upper limb arthritis, dactylitis, psoriasis, nail involvement and family history of SpA, and male gender with pure axial involvement, radiographic sacroiliitis and positive HLA-B27. The number of painful and swollen joints was significantly higher in females [81].

\section{Epidemiology of ankylosing spondylitis}

Incidence-Eight studies addressed the incidence of AS, which varied from 0.44/100.000 persons in Iceland to 7.3/100.000 in US and Northern Norway (Table 4). Using data from the population-based Rochester epidemiology project, collected between 1935 and 1989, the 
overall age- and sex-adjusted incidence rate in Minnesota was 7.3/100.000 person-years [60]. This incidence rate tended to decline between 1935 and 1989, but there was little change in the age at symptom onset or at diagnosis over the 55-year study period. A Finnish study using the nationwide sickness insurance scheme estimated the incidence of AS requiring antirheumatic medications at 6.9/100.000 with no change over time [61]. Studies from Norway and Czechoslovakia showed comparable incidences of AS of 7.3/100.000 and $6.4 / 100.000$ respectively $[62,63]$. The incidence in a study from Greece was found to be lower (1.5/100.000) [64]. The incidence in Japan was estimated at 0.48/100.000 [33].

Prevalence-Thirty -one studies reported on the prevalence of AS, which varied from < $0.01 \%$ in Japan to $1.8 \%$ in Norwegian Samis (Lapps) (Table 1). The highest prevalence of AS was found in a study in Haida indigenous Americans in Canada (6-10\%), in line with the high HLA-B27 positivity among this population [27]. Another study in Alaskan Eskimos however, in whom the prevalence of HLA-B27 was also high (25-40\%) reported a prevalence of only $0.4 \%[45,46]$. Most studies were conducted in Europe and prevalence of AS followed the geographic distribution of HLA-B27 with the highest prevalence of AS in Northern Norway. A study in Samis (Lapps) in whom the prevalence of HLA-B27 is 24\%, reported a prevalence of $1.8 \%$ while an epidemiological survey among males and females in the young middle-aged population in Troms $\varnothing$ showed a prevalence of 1.1-1.4\% [29,31. In contrast, a third study from Northern Norway, showed a prevalence of only $0.31 \%$ [62]. However, this study was hospital-based using medical record data and therefore only included patients with AS under care of a rheumatologist, likely representing the severe spectrum of the disease. In Central and Western Europe, population based studies from Czechoslovakia and Germany reported a relatively high prevalence of AS $(0.9 \%$ and $0.86 \%$ resp.) $[50,63]$. The prevalence of AS in the German blood donor study was later adjusted (for representativeness of blood donors for the general population) to $0.55 \%$ to account for sampling among blood donors [51]. According to a population-based study in Turkey the prevalence of AS in urban areas is 0.49\% [52]. Lower prevalence rates of AS in Europe have been reported in population based studies from Greece (0.24\%) [64]; a sample study of the Finish population $\geq 30$ years of age $(0.15 \%)$ [61]; and in studies from Hungary $(0.23 \%)$ [65], and the Netherlands $(0.24 \%)$ [66]. In an older study in the USA, the overall prevalence of AS in a mainly Caucasian population was reported to be $0.13 \%$ [67]. This study only included patients who sought medical care for their condition, and therefore the reported number is probably an underestimation. On the other hand, NHANES I (1971-1975) examined 6,913 participants between the ages of 25 and 74, obtaining pelvic radiographs in all but 2,010 of these individuals (the latter being women under the age of 50 years) [68]. The prevalence of severe or moderate radiographic sacroiliitis in men was 7.3 per 1000 in men $(0.73 \%)$, and in women over 503.0 per $1000(0.3 \%)$. How many had AS by modified New York criteria was not ascertained, as questions regarding inflammatory back pain (IBP) or measurements of spinal mobility were not done. The prevalence of AS in black Americans might be about one third of that in whites, although there is only indirect evidence for this [35]. Only a few studies reported on the prevalence of AS in Asia. The lowest prevalence of AS was found in Japan $(0.0065 \%)$ [33]. The prevalence in Taiwan was somewhat higher: $0.19-0.54 \%$ [69]. In China, a recent review reported prevalence rates of AS ranging from $0.11-0.41 \%$ in different studies [55]. For the Middle East, limited available 
data showed that AS is relatively uncommon in this part of the world. In Iraq a prevalence was reported of $0.07 \%$ [70] and in Iran of 0.14 [71]. For Australia, there is no evidence to support the occurrence of AS in the indigenous Australian Aborigines with pure ancestry, probably related to the very low frequency of HLA-B27 in this population [72]. Studies from Latin-America and Africa are scarce. A community-based COPCORD door-to-door study in 4059 subjects aged older than 18 years in Mexico, estimated a prevalence of AS of $0.02 \%$ [73]. AS is virtually absent in African blacks. In a study from Togo, there were only nine Togolese AS patients seen among all 2030 patients attending the rheumatology unit of a teaching hospital over a period of 27 months [74]. Also other studies from South-Africa and Zimbabwe showed that AS was extremely rare among African blacks $[74,75]$. This can be expected due to the low prevalence of HLA-B27 in these populations. In addition, a study from Gambia found that the risk of developing AS was also small in HLA-B27 positive Gambians, compared to those of HLA-B27 negative Caucasians, suggesting a non-B27 protective factor reducing the prevalence of AS in this population [75].

\section{HLA-B27 as risk for occurrence and phenotypic heterogeneity (severity) severity of AS}

The prevalence of AS among persons carrying HLA-B27 varies substantially in epidemiological reports throughout the world. In the Netherlands, $2 \%$ of HLA-B27 positive subjects suffer from AS [10], but in northern Norway, 6.7\% of HLA-B27+ may develop AS [29] and according to the blood donor study from Germany 6.4\% [50]. Further, it has been shown that the risk of developing AS is much higher for HLA-B27+ first-degree relatives of HLA-B27+ AS patients (10-30\%) [66].

The phenotype of the disease also differs among HLA B27+ and HLA B27- patients. In a large study of 1080 patient with AS, HLA-B27- patients were significantly older at disease onset [76]. The distribution in age and disease onset was significantly wider in B27- than in B27+ AS. The percentages with childhood disease did not differ significantly, whereas the percentage of late onset was significantly greater among B27- patients with AS. With respect to clinical manifestations, HLA-B27+ patients more frequently suffered from acute anterior uveitis than B27- patients [76]. Observations were conformed in some smaller studies $[77,78]$.

\section{Differences between male and female patients with AS}

AS is traditionally considered as a predominantly male disease, with a commonly reported male:female ratio around 3:1. However, a study of 3000 members of the German Ankylosing Spondylitis Society, found a continuous increase in the percentage of females among patients diagnosed with AS in the last decades [79]. In 1960, only 10\% of diagnosed AS patients were females increasing to $46 \%$ of the patients diagnosed since 1990 . This suggests that the male predominance in AS may be, at least in part, an artifact induced by deficits in the diagnosis of AS among women many decades ago. In the same study it was shown that the age of disease onset was not significantly different between males and females, but there was a significantly longer delay in diagnosis among females. Moreover, a slower progression rate for spinal ankylosis was found in female patients, although they reported significantly more pain and need for drug therapy. 
In a study from Mexico, it has been suggested that females have less severe disease, resulting in less disability [80]. A study with 769 patients with AS from the US (556 men, 213 women) showed no gender differences in cervical or lumbar radiographic severity [81].

\section{Prevalence of extra-articular SpA features in AS}

While the Rome and mNY criteria focused only on axial features to classify AS, extraarticular manifestations, including uveitis, psoriasis and inflammatory bowel disease, are also inherently part of the SpA concept since they occur much more frequently in patients with $\mathrm{SpA} / \mathrm{AS}$ than would be expected from the general population. In the new ASAS axial SpA classification criteria, these features are now part of the classification. When summarizing the literature, the prevalence of uveitis was reported $33.2 \%$ (SD 0.8) in patients with a mean disease duration of 17.0 (SD 1.0) years [82]. The prevalence increased with longer disease duration. There are no exact data on the prevalence of psoriasis and IBD in AS, estimates vary for psoriasis from 10 to $25 \%$ and for IBD from 5 to $10 \%$ of patients [83]. In 236 AS patients included in the German Spondyloarthritis Inception cohort (GESPIC), psoriasis was present in $10.2 \%$ of AS patients and IBD in 2.6\% patients [84]. Another cohort from France (DESIR) included 181 patients fulfilling the $\mathrm{mNY}$ criteria. IBD was present in $7.2 \%$ and psoriasis in $14.4 \%$ of patients [85].

\section{Epidemiology of psoriatic arthritis}

Incidence-The incidence of PsA reported in 7 studies varies from 0.1/100.000 in the Japan to 23.1/100.0000 in Finland (Table 6). The study reporting the lowest incidence in a study from Japan was based on a questionnaire sent to all medical institutions of the country potentially to be attended by patients with SpA [33]. Physicians at the institutes were asked to review the medical records. The incidence rates reported in several studies from Finland, Sweden, Czechoslovakia, Greece, Argentina and the USA were fairly uniform ranging from 3.0 to 8/100.000 [63, 86-90]. However, data from two Finnish studies were conflicting. In one study which examined all patients who were entitled under the nationwide sickness insurance scheme to receive medication for PsA, the annual incidence was 6/100.000 between 1990 and 1995 [86]. In a second study, the incidence was higher (23/100.000) [40]. In this study, information about the study was given through a local newspaper, and subjects attended one health center and two local hospitals for study. Classification was based on the presence of psoriasis and arthritis, excluding RF-positive polyarthritis or spondylitis with psoriasis. A study in the USA used the population-based data resources of the Rochester Epidemiology Project to identify all cased of inflammatory arthritis with a definite diagnosis of psoriasis between 1982 and 1991. The age- and sex-adjusted annual incidence rate was 6.6/100.000. A recent study in the same population, identified a population-based incidence cohort of subjects aged 18 years or over who fulfilled the CASPAR criteria between 1970 and 1999 and studied time trends of PsA incidence [91]. The overall age- and sex-adjusted incidence of PsA per 100.000 significantly increased from 3.6 between 1970 and 1979 to 9.8 between 1990 and 2000 .

Prevalence-The prevalence of psoriatic arthritis is reported for 16 studies, and ranged between $0.02 \%$ in China and Mexico to $0.42 \%$ in Italy (Table 7 ). The majority of studies were performed in Europe and the USA [45, 62, 85, 88, 89, 90, 91]. Cross-sectional 
population surveys that collect data directly from subjects reported a higher prevalence than retrospective studies which were based on medical record review. Most studies used the coexistence of psoriasis and arthritis, others the ESSG criteria. In a study from SouthAmerica (Argentina) based on the CASPAR criteria, the prevalence was $0.07 \%$ [88]. In a North-American study that used the CASPAR criteria (the Rochester epidemiology study), the point prevalence was $0.16 \%$ in 2000 [91]. In a study from Japan the prevalence was very low: $0.001 \%$ [31]. Studies from Africa, large parts of Asia and South-America are lacking.

\section{Prevalence in patients with psoriasis}

Among patients with psoriasis, the prevalence of PsA ranges between 6\% and $42 \%$ in studies from Europe, USA and South-Africa, but figures are lower in Asian countries (1-9\%) [94]. Some recent studies base the classification on the CASPAR criteria: in a study from the UK the prevalence was $13.8 \%$ among psoriasis patients [93] and a Chinese study found a prevalence of 5.8\% [96]. Further, it is recognized that the underdiagnosis of PsA is probably high. In a study of 100 consecutive psoriasis patients without known PsA, the disease was diagnosed in 29\% [97].

\section{Epidemiology of IBD-SpA}

Prevalence-Epidemiological studies of IBD-related SpA are scarce and present only data on prevalence. A prevalence of $0.09 \%$ was estimated in an Italian population study and of $0.02 \%$ in a Swedish study (Table 10). In patients with different forms of SpA about 60-70\% have gut inflammation, which is mainly chronic inflammation discovered by endoscopy [98-100]. In 7\% of SpA patients, this will develop to overt IBD [101].

Prevalence of SpA in patients with IBD-IBD has an estimated prevalence in the general population ranging from 0.01 to $0.5 \%$, with highest numbers reported in studies from Western Europe and the USA [102]. Any spinal or articular SpA manifestation was found in 17 to $62 \%$ of patients. Peripheral arthritis has been reported in 5-28\% of patients, predominantly in Crohn's disease. [103-109]. Twelve to 46\% of patients with IBD fulfilled classification of SpA when applying the ESSG criteria and $2 \%$ to $10 \%$ of patients fulfilled the mNY criteria [103-108, 110-112]. Radiological evidence of sacroiliitis has been reported much more frequently: in $2 \%$ to $18 \%$ on plain X-rays and in $29 \%$ of patients on computed tomography (CT), of which only $3 \%$ were symptomatic $[104,105,107,110,112,113]$. The frequency of HLA-B27 is generally not increased in the IBD population. The prevalence of HLA-B27 in a study in 406 patients with IBD from Norway was $13 \%$, comparable with the general population in that area (10\%), while in patients with c AS, the prevalence of HLAB27 was $73 \%$ [110].

\section{Epidemiology of reactive arthritis}

Incidence-Six studies reported on the incidence of ReA and figures varied from 0.6-3.1/100.000 in Minnesota and Oregon, USA to 28/100.000 in South Sweden (Table 8). Most epidemiologic data of ReA are based on outbreak studies in which patients with joint symptoms during and after the infection are traced with questionnaire or other investigations. The large difference in criteria used, but more importantly in the population sampled, resulted in a wide variation in the estimate of the incidence of ReA which varies 
between 0.6 and 28/100.000 subjects in population studies [116]. In a study from the USA, telephone interviews were performed of individuals with a confirmed infection of Campylobacter, E. Coli, Salmonella, Shigella and Yersinia and patients were asked for new onset rheumatologic symptoms [117]. Possible ReA patients were invited for physical examination. The estimated incidence of ReA was 0.6/100.000 subjects in the area of the outbreak when assuming that none of the non-responders would have SpA, up to 3.1/100.000 when assuming that the non-responders were equally likely to have ReA as the responders. In this study, no association between ReA and HLA-B27 was found. In a study from Czechoslovakia, patients with suspected symptoms of ReA were referred by their general physician to a rheumatologist. An age-standardized incidence of 9.3/100.000 subjects was found [63]. As the course of ReA may be self-limiting, not everyone with ReA might have sought help. Higher incidence rates (10-28/100.000) were found in studies from Scandinavian countries, where the prevalence of HLA-B27 is relatively high $[42,88,118$, 119]. The highest incidence of 28/100.000 was found in a study from Sweden, in which all suspected patients were referred from primary health care centers to a rheumatologist [88]. A recent review showed that, in outbreak studies, the occurrence of ReA after an infection of Campylobacter have been reported in $0.7-1.8 \%$ of patients; after a Shigella infection in 0-6.9\% of patients; after a Yersinia infection in 0-21\% of patients; and after a Salmonella infection in $0-29 \%$ of patients [116].

Prevalence-The prevalence of acute ReA arthritis has been estimated between $0.09 \%$ and $1.0 \%$, depending on criteria used for diagnosis, racial/ethnic differences and the setting in which the study was undertaken (hospital series versus single-source outbreaks versus community-based series) (Table 9) [120]. Interestingly, no data are available from Scandinavian countries.

HLA-B27 in ReA-In contrast to the population based study from the USA, the risk of ReA in HLA-B27-positive patients has been reported in another study to be up to 50 times higher after the exposure of a triggering infection compared to HLA-B27-negative patients in hospital-based studies [121]. However, this number is possibly (partly) biased due to inclusion of the most severe cases in hospital based studies.

\section{Epidemiology of undifferentiated SpA}

No formal definition or classification criteria for USpA exists. Case definitions used comprise either incomplete forms of distinctly defined entities ("pre-radiographic phase of mNY AS", "SpA not fulfilling all required ESSG or AMOR criteria") or disease descriptions that fulfill ESSG or AMOR criteria but cannot be specified further into a specific SpA disease. There are few data on prevalence and incidence of uSpA. Limited data from Europe [48, 50] and Alaska [46] suggest that approximately $40 \%$ of patients with SpA have "undifferentiated" spondyloarthritis. Interestingly, some longitudinal studies are available in which patients with uSpA are followed prospectively. In a study from Brazil, 111 patients with uSpA fulfilling the ESSG and Amor criteria were followed up for 10 years. During the follow-up, 27 patients progressed to AS (24.3\%) and 3 to PsA (2.7\%), while 25 patients (22.5\%) went into remission. HLA-B27 and buttock pain were independently associated with progression to AS [122]. 


\section{Epidemiology and new classification criteria}

\section{Epidemiology of axial SpA}

Axial SpA comprises AS and non-radiographic axial SpA. Epidemiological studies applying these criteria are not yet available and as indicated, these criteria were not developed for use in large population studies. However, there is an interesting report that applied the criteria in a general practitioner setting. In a study in Rotterdam, the Netherlands, 364 patients with chronic low back pain were identified from GP records. They underwent a complete history and physical examination by a rheumatologist, HLA-B27 was assessed and sacroiliac joints were imaged by conventional radiography and MRI. The overall point prevalence of axial SpA was $21.5 \%$ using the ASAS criteria, of which $67.5 \%$ were diagnosed by MRI and $15.5 \%$ were diagnosed by a positive HLA-B27 and two other SpA features. Of all patients, $6.6 \%$ fulfilled the mNY criteria for AS. In this study, three times as many patients were diagnosed as compared to the $\mathrm{mNY}$ criteria using conventional X-ray alone. Adding HLAB27 increased the likelihood of diagnosis of SpA by $68 \%$, and using X-rays increased the likelihood by $75 \%$ [129]

\section{Summary}

Data on prevalence and incidence of the SpA have become particularly important in the last years since more treatments have become available, making it necessary to gain insight whether or not patients have sought medical attention and to know what the impact on society would be in terms of health and costs when all patients would require a specific treatment approach. However, large variations in the population incidence and prevalence of $\mathrm{SpA}$ (as a disease entity) and its subtypes were seen when reviewing the existing literature. Partly, these variations could be attributed by the geographic distribution of HLA-B27, a main risk factor for $\mathrm{SpA}$ and explaining high figures for the Northern countries and low figures in the Japan and Middle Africa. However, also when concentrating on data form West-European countries and the USA, large differences remained. Not only differences in the way the target population was sampled, but also large differences in the approach to operationalize criteria to identify cases contributing to such differences. Overall, SpA as a disease is quite prevalent with figures in Western European countries between 0.3 and 2.5\%. When subtyping SpA, undifferentiated SpA seems to make up about $40 \%$ of these cases. Prevalence of AS and PsA seem about similar in Western countries with figures up to 0.53 $\%$. Although the prevalence of ReA and IBD-SpA seems somewhat lower it should also be realized there were fewer studies available and likely the case finding in epidemiological studies is even more challenging. Most recently, a new disease concept, called axial SpA has been developed including (besides AS) patients with non-radiological axial SpA and criteria for use in a clinical setting have been proposed. It will be particularly challenging to know whether this would be similar when cases are identified in unselected populations.

\section{References}

1. Wright, V.; Moll, JM. Seronegative Polyarthritis. Amsterdam: Publishing Co; 1976.

2. Moll JM, Haslock I, Macrae IF, et al. Associations between ankylosing spondylitis, psoriatic arthritis, Reiter's disease, the intestinal arthropathies, and Behcet's syndrome. Medicine (Baltimore) (1974). 1974 Sep 01.:343-64. [PubMed: 4604133] 
3. Brewerton DA, Hart FD, Nicholls A, et al. Ankylosing spondylitis and HL-A 27. Lancet. 1973; 1(7809):904-7. [PubMed: 4123836]

4. Kellgren JH. Diagnostic criteria for population studies. Bull Rheum Dis. 1962; 13:291-2. [PubMed: 14031789]

5. Gofton JP, Lawrence JS, Bennett PH, et al. Sacro-ilitis in eight populations. Ann Rheum Dis. 1966; 25(6):528-33. [PubMed: 5954317]

6. Bennett, PH. Population studies of the rheumatic diseases. Amsterdam: Excerpta Medica Foundation; 1968.

7. Moll JM, Wright V. New York clinical criteria for ankylosing spondylitis. A statistical evaluation. Ann Rheum Dis. 1973; 32(4):354-63. [PubMed: 4269429]

8. van der Linden S, Valkenburg HA, Cats A. Evaluation of diagnostic criteria for ankylosing spondylitis. A proposal for modification of the New York criteria. Arthritis Rheum. 1984; 27(4): 361-8. [PubMed: 6231933]

9. Mau W, Zeidler H, Mau R, et al. Clinical features and prognosis of patients with possible ankylosing spondylitis. Results of a 10-year followup. J Rheumatol. 1988; 15(7):1109-14. [PubMed: 3262757]

10. Moll JM, Wright V. Psoriatic arthritis. Semin Arthritis Rheum. 1973; 3(1):55-78. [PubMed: 4581554]

11. Helliwell PS, Taylor WJ. Classification and diagnostic criteria for psoriatic arthritis. Ann Rheum Dis. 2005; 64(2):ii3-8. [PubMed: 15708931]

12. Taylor W, Gladman D, Helliwell P, et al. Classification criteria for psoriatic arthritis: development of new criteria from a large international study. Arthritis Rheum. 2006; 54(8):2665-73. [PubMed: 16871531]

13. Braun J, Kingsley G, van der Heijde D, et al. On the difficulties of establishing a consensus on the definition of and diagnostic investigations for reactive arthritis. Results and discussion of a questionnaire prepared for the 4th International Workshop on Reactive Arthritis, Berlin, Germany, July 3-6, 1999. J Rheumatol. 2000; 27(9):2185-92. [PubMed: 10990232]

14. Amor B, Dougados M, Mijiyawa M. [Criteria of the classification of spondylarthropathies]. Rev Rhum Mal Osteoartic. 1990; 57(2):85-9. [PubMed: 2181618]

15. Dougados M, van der Linden S, Juhlin R, et al. The European Spondylarthropathy Study Group preliminary criteria for the classification of spondylarthropathy. Arthritis Rheum. 1991; 34(10): 1218-27. [PubMed: 1930310]

16. Collantes E, Veroz R, Escudero A, et al. Can some cases of 'possible' spondyloarthropathy be classified as 'definite' or 'undifferentiated' spondyloarthropathy? Value of criteria for spondyloarthropathies. Spanish Spondyloarthropathy Study Group. Joint Bone Spine. 2000; 67(6): 516-20. [PubMed: 11195314]

17. Collantes-Estevez E, Cisnal del Mazo A, Munoz-Gomariz E. Assessment of 2 systems of spondyloarthropathy diagnostic and classification criteria (Amor and ESSG) by a Spanish multicenter study. European Spondyloarthropathy Study Group. J Rheumatol. 1995; 22(2):246-51. [PubMed: 7738946]

18. Rudwaleit M, van der Heijde D, Landewe R, et al. The Assessment of SpondyloArthritis International Society classification criteria for peripheral spondyloarthritis and for spondyloarthritis in general. Ann Rheum Dis. 2011; 70(1):25-31. [PubMed: 21109520]

19. Rudwaleit M, van der Heijde D, Landewe R, et al. The development of Assessment of SpondyloArthritis international Society classification criteria for axial spondyloarthritis (part II): validation and final selection. Ann Rheum Dis. 2009; 68(6):777-83. [PubMed: 19297344]

20. Fox DM. Evidence of evidence-based health policy: the politics of systematic reviews in coverage decisions. Health Aff. 2005; 24(1):114-22.

21. Malta M, Cardoso LO, Bastos FI, et al. STROBE initiative: guidelines on reporting observational studies. Rev Saude Publica. 2010; 44(3):559-65. [PubMed: 20549022]

22. Mallen C, Peat G, Croft P. Quality assessment of observational studies is not commonplace in systematic reviews. J Clin Epidemiol. 2006; 59(8):765-9. [PubMed: 16828667] 
23. Sanderson S, Tatt ID, Higgins JP. Tools for assessing quality and susceptibility to bias in observational studies in epidemiology: a systematic review and annotated bibliography. Int $\mathbf{J}$ Epidemiol. 2007; 36(3):666-76. [PubMed: 17470488]

24. Shamliyan TA, Kane RL, Ansari MT, et al. Development quality criteria to evaluate nontherapeutic studies of incidence, prevalence, or risk factors of chronic diseases: pilot study of new checklists. J Clin Epidemiol. 2011; 64(6):637-57. [PubMed: 21071174]

25. Hoy D, Brooks P, Woolf A, et al. Assessing risk of bias in prevalence studies: modification of an existing tool and evidence of interrater agreement. J Clin Epidemiol. 2012; 65(9):934-9. [PubMed: 22742910]

26. Bhatia K, Prasad ML, Barnish G, et al. Antigen and haplotype frequencies at three human leucocyte antigen loci (HLA-A, -B, -C) in the Pawaia of Papua New Guinea. Am J Phys Anthropol. 1988; 75(3):329-40. [PubMed: 3163233]

27. Gofton JP, Chalmers A, Price GE, et al. HL-A 27 and ankylosing spondylitis in B.C. Indians. J Rheumatol. 1984; 11(5):572-3. [PubMed: 6334737]

28. Benevolenskaia LI, Erdes S, Krylov M, et al. [The epidemiology of spondyloarthropathies among the native inhabitants of Chukotka. 2. The prevalence of HLA-B27 in the population and among spondyloarthropathy patients]. Ter Arkh. 1994; 66(5):41-4. [PubMed: 7940337]

29. Gran JT, Husby G, Hordvik M. Prevalence of ankylosing spondylitis in males and females in a young middle-aged population of Tromso, northern Norway. Ann Rheum Dis. 1985; 44(6):35967. [PubMed: 3160312]

30. Gran JT, Mellby AS, Husby G. The prevalence of HLA-B27 in Northern Norway. Scand J Rheumatol. 1984; 13(2):173-6. [PubMed: 6610933]

31. Johnsen K, Gran JT, Dale K, et al. The prevalence of ankylosing spondylitis among Norwegian Samis (Lapps). J Rheumatol. 1992; 19(10):1591-4. [PubMed: 1464873]

32. Mustafa KN, Hammoudeh M, Khan MA. HLA-B27 Prevalence in Arab Populations and Among Patients with Ankylosing Spondylitis. J Rheumatol. 2012

33. Hukuda S, Minami M, Saito T, et al. Spondyloarthropathies in Japan: nationwide questionnaire survey performed by the Japan Ankylosing Spondylitis Society. J Rheumatol. 2001; 28(3):554-9. [PubMed: 11296958]

34. Khan MA. HLA-B27 and its subtypes in world populations. Curr Opin Rheumatol. 1995; 7(4): 263-9. [PubMed: 7547102]

35. Khan MA. Race-related differences in HLA association with ankylosing spondylitis and Reiter's disease in American blacks and whites. J Natl Med Assoc. 1978; 70(1):41-2. [PubMed: 702543]

36. al-Arfaj A. Profile of ankylosing spondylitis in Saudi Arabia. Clin Rheumatol. 1996; 15(3):287-9. [PubMed: 8793262]

37. Alharbi SA, Mahmoud FF, Al Awadi A, et al. Association of MHC class I with spondyloarthropathies in Kuwait. Eur J Immunogenet. 1996; 23(1):67-70. [PubMed: 8834924]

38. Uppal SS, Abraham M, Chowdhury RI, et al. Ankylosing spondylitis and undifferentiated spondyloarthritis in Kuwait: a comparison between Arabs and South Asians. Clin Rheumatol. 2006; 25(2):219-24. [PubMed: 16240074]

39. Reveille JD, Hirsch R, Dillon CF, et al. The Prevalence of HLA-B27 in the United States: Data from the U.S. National Health and Nutrition Examination Survey, 2009. Arthritis Rheum. 2012; 64(5):1407-11. [PubMed: 22139851]

40. Reveille JD. Major histocompatibility genes and ankylosing spondylitis. Best Pract Res Clin Rheumatol. 2006; 20(3):601-9. [PubMed: 16777585]

41. Thomas GP, Brown MA. Genetics and genomics of ankylosing spondylitis. Immunol Rev. 2010; 233(1):162-80. [PubMed: 20192999]

42. Savolainen E, Kaipiainen-Seppanen O, Kroger L, et al. Total incidence and distribution of inflammatory joint diseases in a defined population: results from the Kuopio 2000 arthritis survey. J Rheumatol. 2003; 30(11):2460-8. [PubMed: 14677193]

43. Kaipiainen-Seppanen O, Aho K. Incidence of chronic inflammatory joint diseases in Finland in 1995. J Rheumatol. 2000; 27(1):94-100. [PubMed: 10648024]

44. Munoz-Fernandez S, de Miguel E, Cobo-Ibanez T, et al. Early spondyloarthritis: results from the pilot registry ESPIDEP. Clin Exp Rheumatol. 2010; 28(4):498-503. [PubMed: 20659413] 
45. Boyer GS, Lanier AP, Templin DW. Prevalence rates of spondyloarthropathies, rheumatoid arthritis, and other rheumatic disorders in an Alaskan Inupiat Eskimo population. J Rheumatol. 1988; 15(4):678-83. [PubMed: 3260953]

46. Boyer GS, Templin DW, Cornoni-Huntley JC, et al. Prevalence of spondyloarthropathies in Alaskan Eskimos. J Rheumatol. 1994; 21(12):2292-7. [PubMed: 7699631]

47. Saraux A, Guillemin F, Guggenbuhl P, et al. Prevalence of spondyloarthropathies in France: 2001. Ann Rheum Dis. 2005; 64(10):1431-5. [PubMed: 15817661]

48. Saraux A, Guedes C, Allain J, et al. Prevalence of rheumatoid arthritis and spondyloarthropathy in Brittany, France. Societe de Rhumatologie de l'Ouest. J Rheumatol. 1999; 26(12):2622-7. [PubMed: 10606373]

49. Adomaviciute D, Pileckyte M, Baranauskaite A, et al. Prevalence survey of rheumatoid arthritis and spondyloarthropathy in Lithuania. Scand J Rheumatol. 2008; 37(2):113-9. [PubMed: 18415768]

50. Braun J, Bollow M, Remlinger G, et al. Prevalence of spondylarthropathies in HLA-B27 positive and negative blood donors. Arthritis Rheum. 1998; 41(1):58-67. [PubMed: 9433870]

51. Akkoc N, Khan MA. Overestimation of the prevalence of ankylosing spondylitis in the Berlin study: comment on the article by Braun et al. Arthritis Rheum. 2005; 52(12):4048-9. author reply 9-50. [PubMed: 16320356]

52. Onen F, Akar S, Birlik M, et al. Prevalence of ankylosing spondylitis and related spondyloarthritides in an urban area of Izmir, Turkey. J Rheumatol. 2008; 35(2):305-9. [PubMed: 18085733]

53. De Angelis R, Salaffi F, Grassi W. Prevalence of spondyloarthropathies in an Italian population sample: a regional community-based study. Scand J Rheumatol. 2007; 36(1):14-21. [PubMed: 17454930]

54. Bruges-Armas J, Lima C, Peixoto MJ, et al. Prevalence of spondyloarthritis in Terceira, Azores: a population based study. Ann Rheum Dis. 2002; 61(6):551-3. [PubMed: 12006333]

55. Andrianakos A, Trontzas P, Christoyannis F, et al. Prevalence of rheumatic diseases in Greece: a cross-sectional population based epidemiological study. The ESORDIG Study. J Rheumatol. 2003; 30(7):1589-601. [PubMed: 12858464]

56. Reveille JD, Witter JP, Weisman MH. Prevalence of axial spondylarthritis in the United States: estimates from a cross-sectional survey. Arthritis Care Res (Hoboken). 2012; 64(6):905-10. [PubMed: 22275150]

57. Ng SC, Liao Z, Yu DT, et al. Epidemiology of spondyloarthritis in the People's Republic of China: review of the literature and commentary. Semin Arthritis Rheum. 2007; 37(1):39-47. [PubMed: 17350674]

58. Chaiamnuay P, Darmawan J, Muirden KD, et al. Epidemiology of rheumatic disease in rural Thailand: a WHO-ILAR COPCORD study. Community Oriented Programme for the Control of Rheumatic Disease. J Rheumatol. 1998; 25(7):1382-7. [PubMed: 9676773]

59. Minh Hoa TT, Darmawan J, Chen SL, et al. Prevalence of the rheumatic diseases in urban Vietnam: a WHO-ILAR COPCORD study. J Rheumatol. 2003; 30(10):2252-6. [PubMed: 14528525]

60. Carbone LD, Cooper C, Michet CJ, et al. Ankylosing spondylitis in Rochester, Minnesota, 1935-1989: Is the epidemiology changing? Arthritis and Rheumatism. 1992; 35(12):1476-82. [PubMed: 1472124]

61. Kaipiainen-Seppanen O, Aho K, Heliovaara M. Incidence and prevalence of ankylosing spondylitis in Finland. J Rheumatol. 1997; 24(3):496-9. [PubMed: 9058655]

62. Bakland G, Nossent HC, Gran JT. Incidence and prevalence of ankylosing spondylitis in Northern Norway. Arthritis Rheum. 2005; 53(6):850-5. [PubMed: 16342091]

63. Hanova P, Pavelka K, Holcatova I, et al. Incidence and prevalence of psoriatic arthritis, ankylosing spondylitis, and reactive arthritis in the first descriptive population-based study in the Czech Republic. Scand J Rheumatol. 2010; 39(4):310-7. [PubMed: 20476864]

64. Alamanos Y, Papadopoulos NG, Voulgari PV, et al. Epidemiology of ankylosing spondylitis in Northwest Greece, 1983-2002. Rheumatology (Oxford). 2004; 43(5):615-8. [PubMed: 14872102] 
65. Gomor B, Gyodi E, Bakos L. Distribution of HLA B27 and ankylosing spondylitis in the Hungarian population. J Rheumatol Suppl. 1977; 3:33-5. [PubMed: 266594]

66. van der Linden S, Valkenburg H, Cats A. The risk of developing ankylosing spondylitis in HLAB27 positive individuals: a family and population study. Br J Rheumatol. 1983; 22(4 Suppl 2):189. [PubMed: 6606472]

67. Carter ET, McKenna CH, Brian DD, et al. Epidemiology of Ankylosing spondylitis in Rochester, Minnesota, 1935-1973. Arthritis Rheum. 1979; 22(4):365-70. [PubMed: 426882]

68. Maurer K. Basic Data on Arthritis: Knee, Hip, and Sacroiliac Joints in Adults Ages 25-74 Years, United States, 1971-1975. Vital Health Stat. 1979; 11(213):1-31.

69. Chou CT, Pei L, Chang DM, et al. Prevalence of rheumatic diseases in Taiwan: a population study of urban, suburban, rural differences. Journal of Rheumatology. 1994; 21(2):302-6. [PubMed: 8182641]

70. Al-Rawi ZS, Al-Shakarchi HA, Hasan F, et al. Ankylosing spondylitis and its association with the histocompatibility antigen HL-A B27: an epidemiological and clinical study. Rheumatol Rehabil. 1978; 17(2):72-5. [PubMed: 663524]

71. Davatchi F, Jamshidi AR, Banihashemi AT, et al. WHO-ILAR COPCORD Study (Stage 1, Urban Study) in Iran. J Rheumatol. 2008; 35(7):1384. [PubMed: 18464299]

72. Roberts-Thomson RA, Roberts-Thomson PJ. Rheumatic disease and the Australian aborigine. Ann Rheum Dis. 1999; 58(5):266-70. [PubMed: 10225809]

73. Alvarez-Nemegyei J, Pelaez-Ballestas I, Sanin LH, et al. Prevalence of musculoskeletal pain and rheumatic diseases in the southeastern region of Mexico. A COPCORD-based community survey. J Rheumatol Suppl. 2011; 86:21-5. [PubMed: 21196595]

74. Mijiyawa M. Spondyloarthropathies in patients attending the rheumatology unit of Lome Hospital. J Rheumatol. 1993; 20(7):1167-9. [PubMed: 8371211]

75. Stein M, Davis P, Emmanuel J, et al. The spondyloarthropathies in Zimbabwe: a clinical and immunogenetic profile. J Rheumatol. 1990; 17(10):1337-9. [PubMed: 2254892]

76. Feldtkeller E, Khan MA, van der Heijde D, et al. Age at disease onset and diagnosis delay in HLAB27 negative vs. positive patients with ankylosing spondylitis. Rheumatology International. 2003; 23(2):61-6. [PubMed: 12634937]

77. Linssen A. B27+ disease versus B27- disease. Scand J Rheumatol Suppl. 1990; 87:111-8. discussion 8-9. [PubMed: 2259879]

78. Awada H, Abi-Karam G, Baddoura R, et al. Clinical, radiological, and laboratory findings in Lebanese spondylarthropathy patients according to HLA-B27 status. Joint Bone Spine. 2000; 67(3):194-8. [PubMed: 10875317]

79. Feldtkeller E, Bruckel J, Khan MA. Scientific contributions of ankylosing spondylitis patient advocacy groups. Curr Opin Rheumatol. 2000; 12(4):239-47. [PubMed: 10910174]

80. Jimenez-Balderas FJ, Mintz G. Ankylosing spondylitis: clinical course in women and men. J Rheumatol. 1993; 20(12):2069-72. [PubMed: 7516975]

81. Jang JH, Ward MM, Rucker AN, et al. Ankylosing Spondylitis: Patterns of Radiographic Involvement--A Re-examination of Accepted Principles in a Cohort of 769 Patients. Radiology. 2011; 258(1):192-8. T80. [PubMed: 20971774]

82. Zeboulon N, Dougados M, Gossec L. Prevalence and characteristics of uveitis in the spondyloarthropathies: a systematic literature review. Ann Rheum Dis. 2008; 67(7):955-9. [PubMed: 17962239]

83. El Maghraoui A. Extra-articular manifestations of ankylosing spondylitis: prevalence, characteristics and therapeutic implications. Eur J Intern Med. 2011; 22(6):554-60. [PubMed: 22075279]

84. Rudwaleit M, Haibel H, Baraliakos X, et al. The early disease stage in axial spondylarthritis: results from the German Spondyloarthritis Inception Cohort. Arthritis \& Rheumatism. 2009; 60(3):717-27. [PubMed: 19248087]

85. Dougados M, d'Agostino MA, Benessiano J, et al. The DESIR cohort: a 10-year follow-up of early inflammatory back pain in France: study design and baseline characteristics of the 708 recruited patients. Joint Bone Spine. 2011; 78(6):598-603. [PubMed: 21458351] 
86. Kaipiainen-Seppanen O. Incidence of psoriatic arthritis in Finland. Br J Rheumatol. 1996; 35(12): 1289-91. [PubMed: 9010058]

87. Shbeeb M, Uramoto KM, Gibson LE, et al. The epidemiology of psoriatic arthritis in Olmsted County, Minnesota, USA, 1982-1991. J Rheumatol. 2000; 27(5):1247-50. [PubMed: 10813295]

88. Soderlin MK, Borjesson O, Kautiainen H, et al. Annual incidence of inflammatory joint diseases in a population based study in southern Sweden. Ann Rheum Dis. 2002; 61(10):911-5. [PubMed: 12228162]

89. Alamanos Y, Papadopoulos NG, Voulgari PV, et al. Epidemiology of psoriatic arthritis in northwest Greece, 1982-2001. J Rheumatol. 2003; 30(12):2641-4. [PubMed: 14719208]

90. Soriano ER, Rosa J, Velozo E, et al. Incidence and prevalence of psoriatic arthritis in Buenos Aires, Argentina: a 6-year health management organization-based study. Rheumatology (Oxford). 2011; 50(4):729-34. [PubMed: 21134962]

91. Wilson FC, Icen M, Crowson CS, et al. Time trends in epidemiology and characteristics of psoriatic arthritis over 3 decades: a population-based study. J Rheumatol. 2009; 36(2):361-7. [PubMed: 19208565]

92. Madland TM, Apalset EM, Johannessen AE, et al. Prevalence, disease manifestations, and treatment of psoriatic arthritis in Western Norway. J Rheumatol. 2005; 32(10):1918-22. [PubMed: 16206347]

93. Love TJ, Gudbjornsson B, Gudjonsson JE, et al. Psoriatic arthritis in Reykjavik, Iceland: prevalence, demographics, and disease course. J Rheumatol. 2007; 34(10):2082-8. [PubMed: 17696270]

94. Tam LS, Leung YY, Li EK. Psoriatic arthritis in Asia. Rheumatology (Oxford). 2009; 48(12): 1473-7. [PubMed: 19713440]

95. Ibrahim G, Waxman R, Helliwell PS. The prevalence of psoriatic arthritis in people with psoriasis. Arthritis Rheum. 2009; 61(10):1373-8. [PubMed: 19790120]

96. Yang Q, Qu L, Tian H, et al. Prevalence and characteristics of psoriatic arthritis in Chinese patients with psoriasis. J Eur Acad Dermatol Venereol. 2011; 25(12):1409-14. [PubMed: 21349114]

97. Haroon M, Kirby B, Fitzgerald O. High prevalence of psoriatic arthritis in patients with severe psoriasis with suboptimal performance of screening questionnaires. Ann Rheum Dis. 2012

98. De Vos M, Cuvelier C, Mielants H, et al. Ileocolonoscopy in seronegative spondylarthropathy. Gastroenterology. 1989; 96(2 Pt 1):339-44. [PubMed: 2637670]

99. Mielants H, Veys EM, Goemaere S, et al. Gut inflammation in the spondyloarthropathies: clinical, radiologic, biologic and genetic features in relation to the type of histology. A prospective study. $\mathrm{J}$ Rheumatol. 1991; 18(10):1542-51. [PubMed: 1765980]

100. Simenon G, Van Gossum A, Adler M, et al. Macroscopic and microscopic gut lesions in seronegative spondyloarthropathies. J Rheumatol. 1990; 17(11):1491-4. [PubMed: 1980311]

101. De Vos M, Mielants H, Cuvelier C, et al. Long-term evolution of gut inflammation in patients with spondyloarthropathy. Gastroenterology. 1996; 110(6):1696-703. [PubMed: 8964393]

102. Molodecky NA, Soon IS, Rabi DM, et al. Increasing incidence and prevalence of the inflammatory bowel diseases with time, based on systematic review. Gastroenterology. 2012; 142(1):46-54. e42. quiz e30. [PubMed: 22001864]

103. Beslek A, Onen F, Birlik M, et al. Prevalence of spondyloarthritis in Turkish patients with inflammatory bowel disease. Rheumatol Int. 2009; 29(8):955-7. [PubMed: 19082597]

104. de Vlam K, Mielants H, Cuvelier C, et al. Spondyloarthropathy is underestimated in inflammatory bowel disease: prevalence and HLA association. J Rheumatol. 2000; 27(12):2860 5. [PubMed: 11128677]

105. Lanna CC, Ferrari Mde L, Rocha SL, et al. A cross-sectional study of 130 Brazilian patients with Crohn's disease and ulcerative colitis: analysis of articular and ophthalmologic manifestations. Clin Rheumatol. 2008; 27(4):503-9. [PubMed: 18097711]

106. Protzer U, Duchmann R, Hohler T, et al. [Enteropathic spondylarthritis in chronic inflammatory bowel diseases: prevalence, manifestation pattern and HLA association]. Med Klin (Munich). 1996; 91(6):330-5. [PubMed: 8767304]

107. Rodriguez VE, Costas PJ, Vazquez M, et al. Prevalence of spondyloarthropathy in Puerto Rican patients with inflammatory bowel disease. Ethn Dis. 2008; 18(2 Suppl 2):S2-225. 9. 
108. Salvarani C, Vlachonikolis IG, van der Heijde DM, et al. Musculoskeletal manifestations in a population-based cohort of inflammatory bowel disease patients. Scand J Gastroenterol. 2001; 36(12):1307-13. [PubMed: 11761022]

109. Palm O, Moum B, Jahnsen J, et al. The prevalence and incidence of peripheral arthritis in patients with inflammatory bowel disease, a prospective population-based study (the IBSEN study). Rheumatology (Oxford). 2001; 40(11):1256-61. [PubMed: 11709609]

110. Palm O, Moum B, Ongre A, et al. Prevalence of ankylosing spondylitis and other spondyloarthropathies among patients with inflammatory bowel disease: a population study (the IBSEN study). J Rheumatol. 2002; 29(3):511-5. [PubMed: 11908564]

111. Scarpa R, del Puente A, D'Arienzo A, et al. The arthritis of ulcerative colitis: clinical and genetic aspects. J Rheumatol. 1992; 19(3):373-7. [PubMed: 1578450]

112. Turkcapar N, Toruner M, Soykan I, et al. The prevalence of extraintestinal manifestations and HLA association in patients with inflammatory bowel disease. Rheumatol Int. 2006; 26(7):6638. [PubMed: 16136311]

113. Scott WW Jr, Fishman EK, Kuhlman JE, et al. Computed tomography evaluation of the sacroiliac joints in Crohn disease. Radiologic/clinical correlation. Skeletal Radiol. 1990; 19(3):207-10. [PubMed: 2333561]

114. Locht H, Krogfelt KA. Comparison of rheumatological and gastrointestinal symptoms after infection with Campylobacter jejuni/coli and enterotoxigenic Escherichia coli. Ann Rheum Dis. 2002; 61(5):448-52. [PubMed: 11959770]

115. Hannu T, Puolakkainen M, Leirisalo-Repo M. Chlamydia pneumoniae as a triggering infection in reactive arthritis. Rheumatology (Oxford). 1999; 38(5):411-4. [PubMed: 10371278]

116. Hannu T. Reactive arthritis. Best Pract Res Clin Rheumatol. 2011; 25(3):347-57. [PubMed: 22100285]

117. Townes JM, Deodhar AA, Laine ES, et al. Reactive arthritis following culture-confirmed infections with bacterial enteric pathogens in Minnesota and Oregon: a population-based study. Ann Rheum Dis. 2008; 67(12):1689-96. [PubMed: 18272671]

118. Isomaki H, Raunio J, von Essen R, et al. Incidence of inflammatory rheumatic diseases in Finland. Scand J Rheumatol. 1978; 7(3):188-92. [PubMed: 310157]

119. Kvien TK, Glennas A, Melby K, et al. Reactive arthritis: incidence, triggering agents and clinical presentation. J Rheumatol. 1994; 21(1):115-22. [PubMed: 8151565]

120. Pope JE, Krizova A, Garg AX, et al. Campylobacter reactive arthritis: a systematic review. Semin Arthritis Rheum. 2007; 37(1):48-55. [PubMed: 17360026]

121. Aho K, Ahvonen P, Lassus A, et al. HL-A antigen 27 and reactive arthritis. Lancet. 1973; 2(7821):157. [PubMed: 4124084]

122. Sampaio-Barros PD, Bortoluzzo AB, Conde RA, et al. Undifferentiated spondyloarthritis: a longterm followup. J Rheumatol. 2010; 37(6):1195-9. [PubMed: 20436080]

123. Trontzas P, Andrianakos A, Miyakis S, et al. Seronegative spondyloarthropathies in Greece: a population-based study of prevalence, clinical pattern, and management. The ESORDIG study. Clin Rheumatol. 2005; 24(6):583-9. [PubMed: 15864686]

124. Haglund E, Bremander AB, Petersson IF, et al. Prevalence of spondyloarthritis and its subtypes in southern Sweden. Annals of the Rheumatic Diseases. 2011; 70(6):943-8. [PubMed: 21288961]

125. Alexeeva L, Krylov M, Vturin V, et al. Prevalence of spondyloarthropathies and HLA-B27 in the native population of Chukotka, Russia. J Rheumatol. 1994; 21(12):2298-300. [PubMed: 7699632]

126. Farooqi A, Gibson T. Prevalence of the major rheumatic disorders in the adult population of north Pakistan. Br J Rheumatol. 1998; 37(5):491-5. [PubMed: 9651074]

127. Liao ZT, Pan YF, Huang JL, et al. An epidemiological survey of low back pain and axial spondyloarthritis in a Chinese Han population. Scand J Rheumatol. 2009; 38(6):455-9. [PubMed: 19922021]

128. Geirsson AJ, Eyjolfsdottir H, Bjornsdottir G, et al. Prevalence and clinical characteristics of ankylosing spondylitis in Iceland - a nationwide study. Clinical \& Experimental Rheumatology. 2010; 28(3):333-40. [PubMed: 20406616] 
129. van Onna M, Jurik AG, van der Heijde D, van Tubergen A, Heuft-Dorenbosch L, Landewé R. HLA-B27 and gender independently determine the likelihood of a positive MRI of the sacroiliac joints in patients with early inflammatory back pain: a 2-year MRI follow-up study. Ann Rheum Dis. 2011; 70(11):1981-5. [PubMed: 21859694] 


\section{Key points}

- Data on incidence and prevalence become increasingly important not only for clinicians when trying to understand disease patterns but also for policy makers that need to be informed on budget of health impact of disease and their treatment at the population level. Hence the need for accurate data on incidence and prevalence.

- The variation in incidence and prevalence of SpA as a disease and the SpA subtypes varies highly and this cannot only be attributed to geographical variation in the prevalence of HLA-B27. As part of this variation likely will be explained by variation in quality and bias of the methodological approaches, the recently generic guidelines for performance of studies on incidence and prevalence could be adapted for use in the $\mathrm{SpA}$

- A particular challenge will be to agree on a series of approaches with acceptable (low) risk of bias that could operationalize the present classification criteria (which are developed for use in a (specialized) clinical setting) for use in large epidemiological studies.

- While a large part of the SpA subtypes in epidemiological studies are as yet classified as 'undifferentiated SpA', this diagnosis will likely disappear with the acceptance of the new concepts and classification of axial- and peripheral SpA. The application of these criteria in epidemiological studies requires further consideration.

- Remarkably limited data are available on the prevalence of IBD related SpA and $\mathrm{ReA}$. The new peripheral SpA criteria would likely encompass both entities, but the transient nature of ReA makes prevalence estimates especially challenging. 


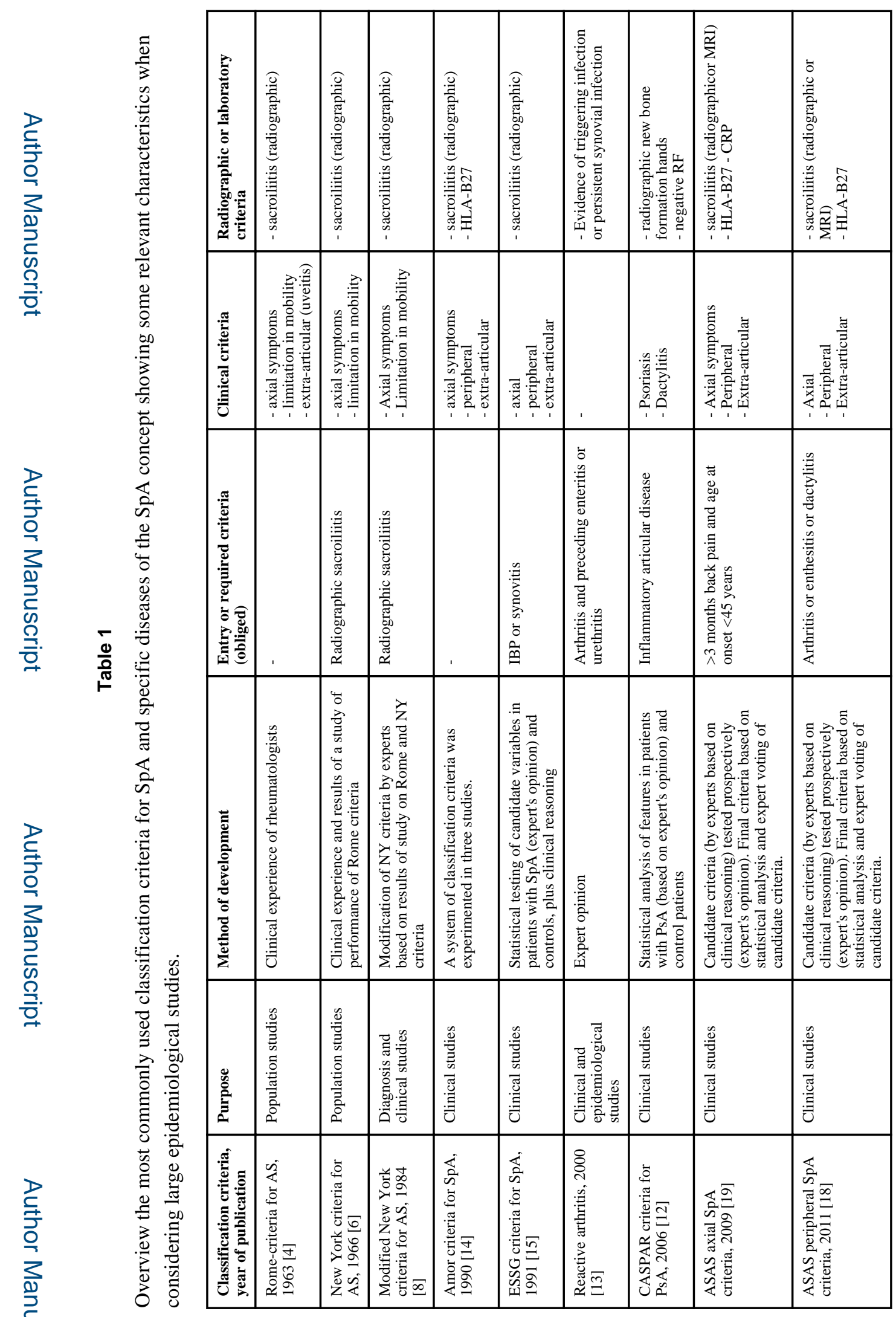

Rheum Dis Clin North Am. Author manuscript; available in PMC 2015 June 17. 


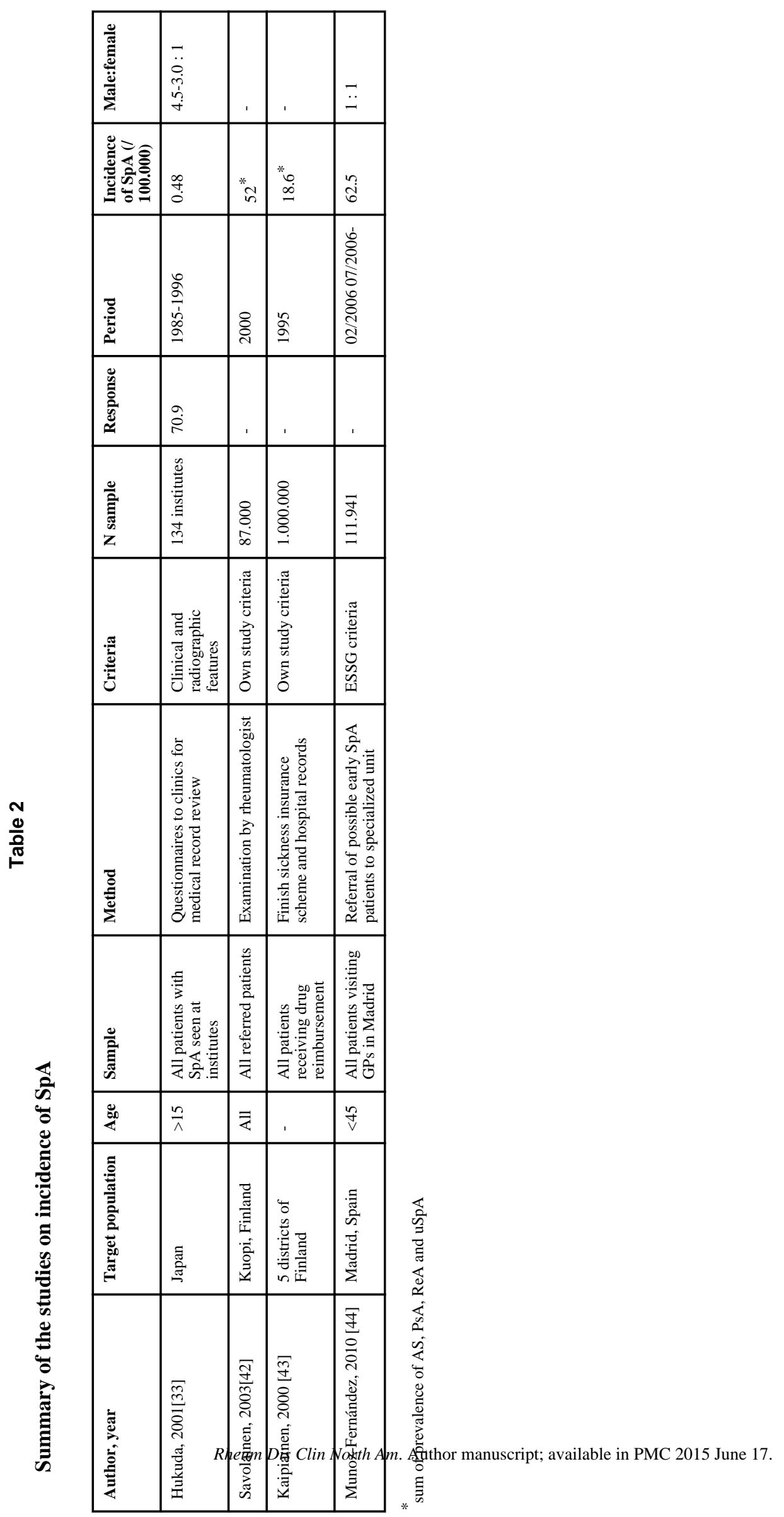

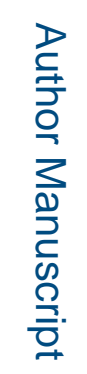




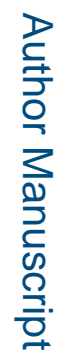

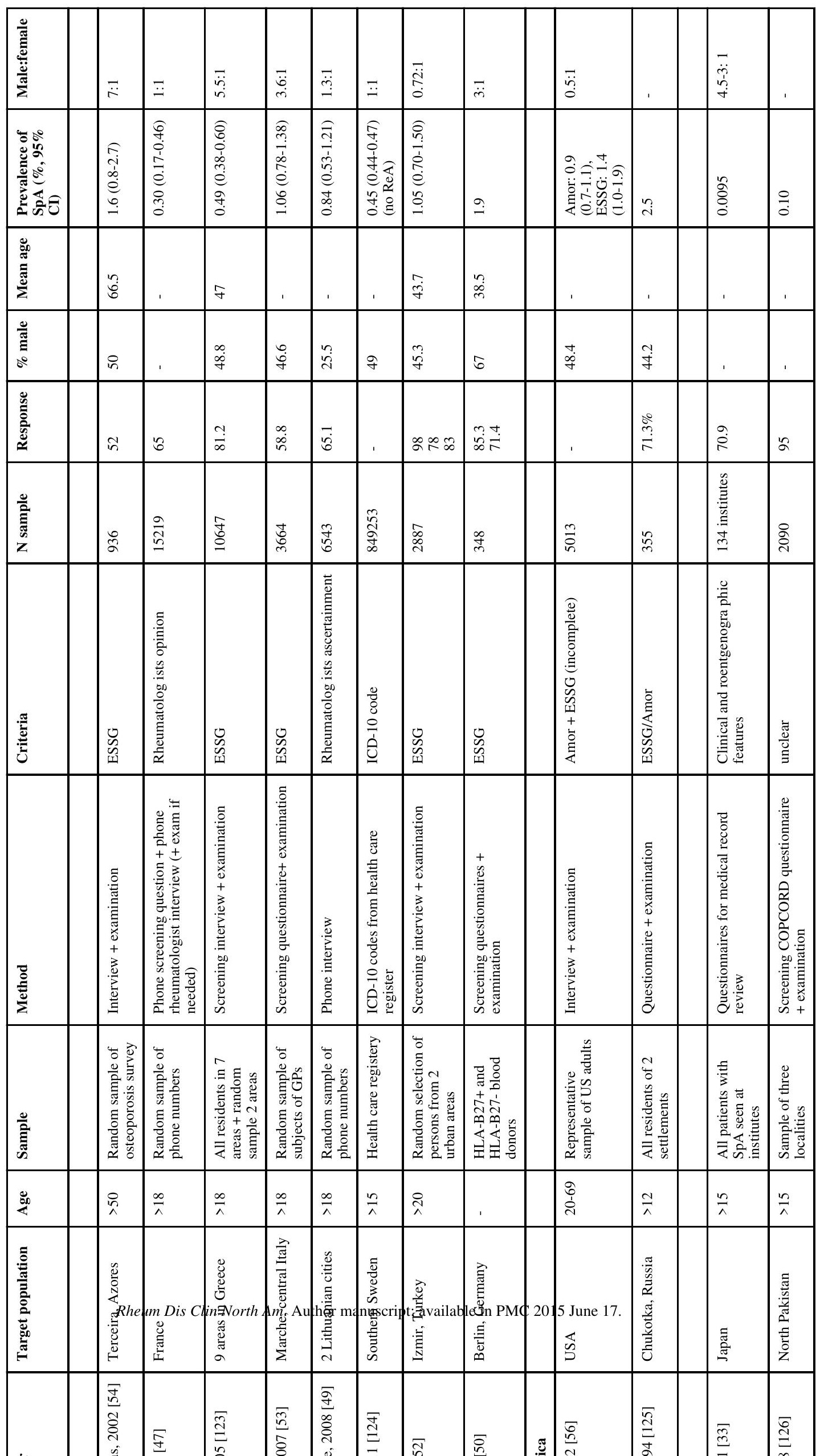




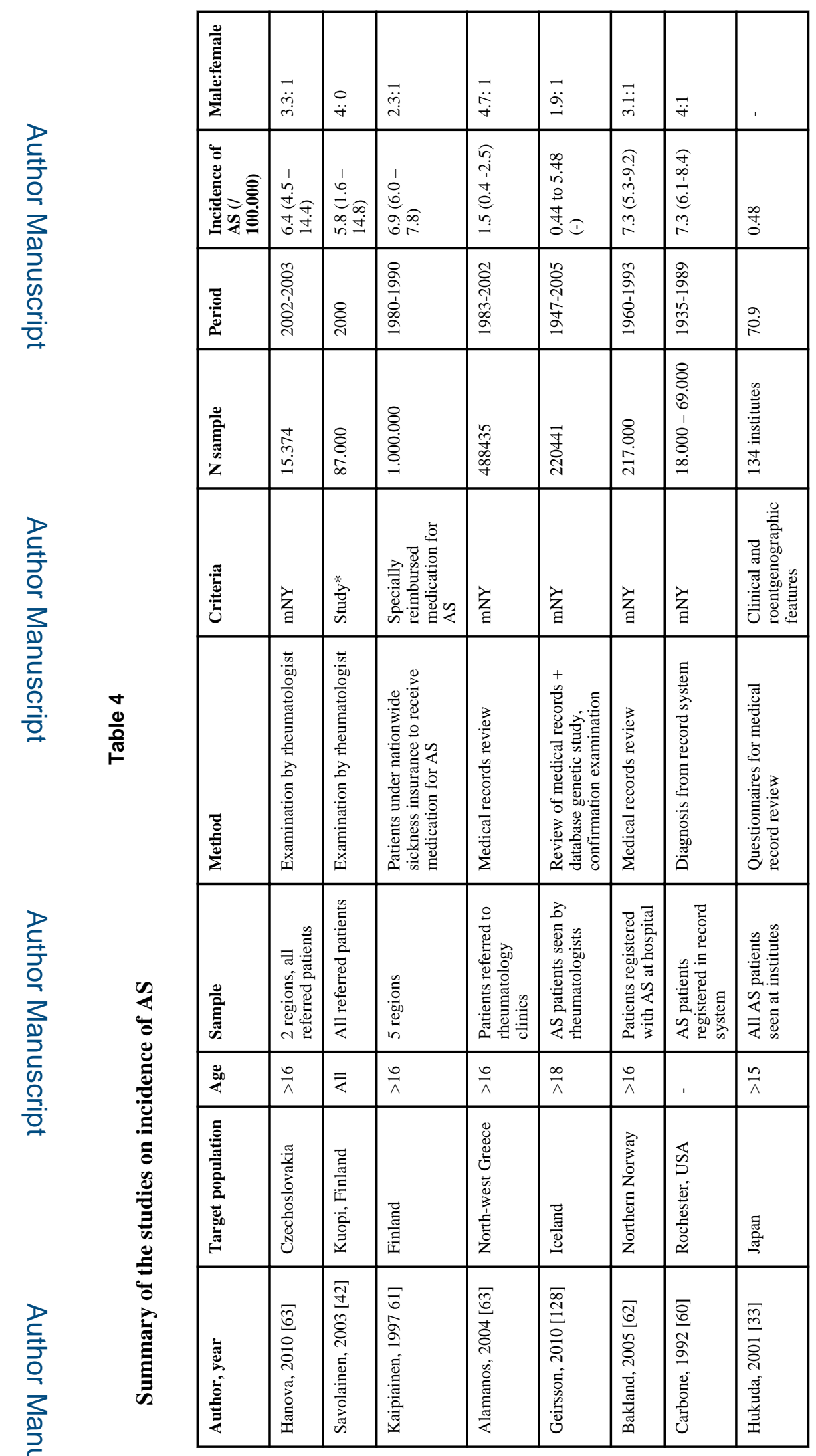

Rheum Dis Clin North Am. Author manuscript; available in PMC 2015 June 17. 


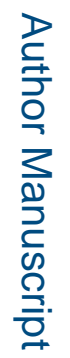

\begin{tabular}{|c|c|c|c|c|c|c|c|c|c|c|c|c|c|c|c|}
\hline 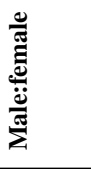 & $\begin{array}{l}\ddot{\ddot{\sigma}} \\
\dot{\sigma}\end{array}$ & & $\overrightarrow{\ddot{i}}$ & $\overrightarrow{\ddot{b}}$ & $\begin{array}{l}\ddot{\sim} \\
\ddot{+}\end{array}$ & $\ddot{g}$ & ' & , & $\vec{i}$ & $\stackrel{\vec{ت}}{\dot{m}}$ & $\begin{array}{l}\overrightarrow{.} \\
\ddot{b} \\
\stackrel{0}{ } \\
\dot{m}\end{array}$ & $\overrightarrow{\ddot{C}}$ & 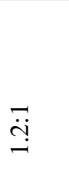 & , & $\overline{\ddot{m}}$ \\
\hline 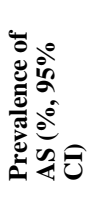 & $\begin{array}{l}0 \\
\overline{0} \\
0 \\
0 \\
0 \\
0 \\
0 \\
0 \\
0\end{array}$ & 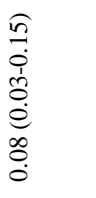 & $\begin{array}{l}\widehat{\hat{\jmath}} \\
0 \\
0 \\
1 \\
0 \\
0 \\
0 \\
n \\
0 \\
0\end{array}$ & 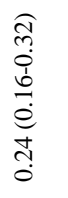 & 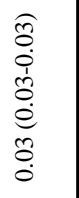 & 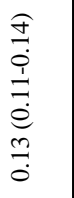 & 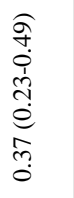 & $\stackrel{+}{\sim}$ & 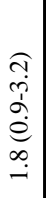 & $\stackrel{\text { ஸ̆ }}{0}$ & $\begin{array}{l}\stackrel{+}{-} \\
\stackrel{+}{\leftrightarrows}\end{array}$ & 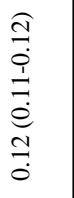 & 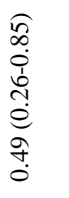 & $\begin{array}{l}\stackrel{0}{\infty} \\
\stackrel{0}{0}\end{array}$ & $\frac{m}{0}$ \\
\hline 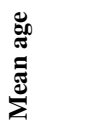 & ' & & ' & f & & ' & & I & 1 & ' & ' & 1 & $\stackrel{\vec{f}}{\ddot{f}}$ & $\begin{array}{l}n \\
\infty \\
\infty\end{array}$ & , \\
\hline 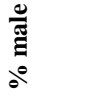 & ' & ' & ' & $\begin{array}{l}\infty \\
\stackrel{\infty}{+}\end{array}$ & I & ' & $\begin{array}{l}0 \\
\dot{b}\end{array}$ & , & $\ddot{n}$ & $\bar{n}$ & $\stackrel{n}{n}$ & g & $\stackrel{m}{\mathfrak{f}}$ & $\hat{\sigma}$ & I \\
\hline 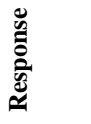 & ' & 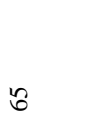 & ฉ & $\frac{N}{\infty}$ & & $\frac{\nabla}{\sigma}$ & $\begin{array}{l}\infty \\
\infty \\
\infty \\
n\end{array}$ & $\mathbb{z}$ & $\stackrel{\sim}{\infty}$ & ' & 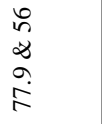 & ' & $\begin{array}{l}\Re \\
\infty \\
\infty \\
\infty \\
\infty\end{array}$ & 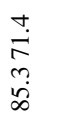 & , \\
\hline 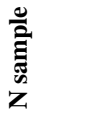 & 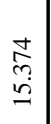 & $\underset{\stackrel{\approx}{n}}{\stackrel{\vartheta}{n}}$ & $\underset{\infty}{\$}$ & $\underset{\overbrace{}}{\stackrel{f}{d}}$ & \begin{tabular}{l}
$\tilde{n}$ \\
\multirow{\infty}{\infty}{} \\
$\infty$ \\
$\dot{+}$
\end{tabular} & $\begin{array}{l}\vec{J} \\
\text { ते } \\
\text { ते }\end{array}$ & 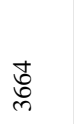 & $\stackrel{n}{\check{n}}$ & $\stackrel{\Xi}{\Xi}$ & $\begin{array}{l}\stackrel{8}{o} \\
\stackrel{\sim}{N}\end{array}$ & $\frac{\vec{\sim}}{\stackrel{\sim}{े}}$ & 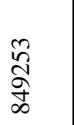 & 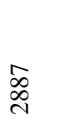 & $\stackrel{\infty}{\stackrel{\infty}{m}}$ & $\begin{array}{l}n \\
1 \\
8 \\
\delta \\
\dot{m} \\
m\end{array}$ \\
\hline Uू & 弁 & 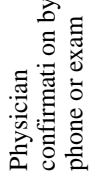 & 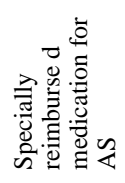 & 忘 & 忞 & 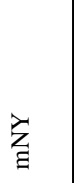 & 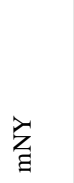 & 齐 & 乙 & 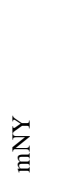 & 之े & 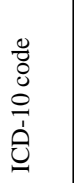 & 忘 & 空 & $\grave{z}$ \\
\hline 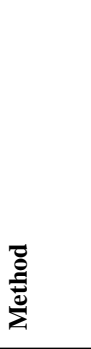 & 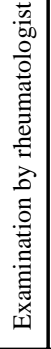 & 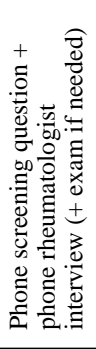 & 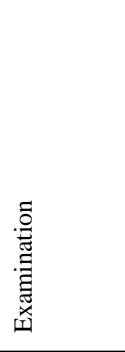 & 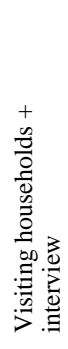 & 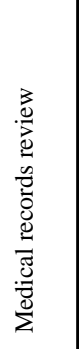 & 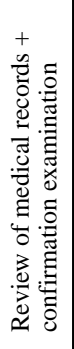 & 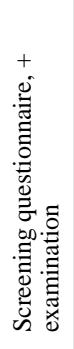 & 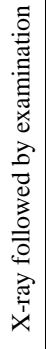 & 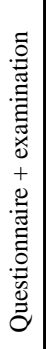 & 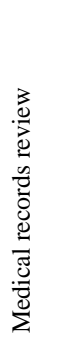 & 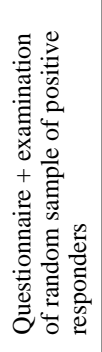 & 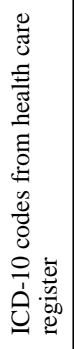 & 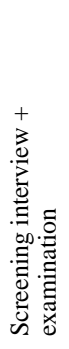 & 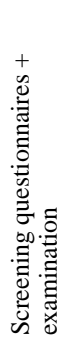 & 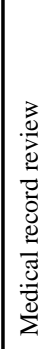 \\
\hline 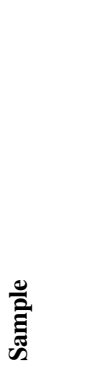 & 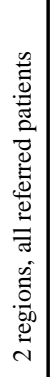 & 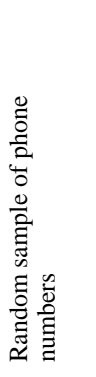 & 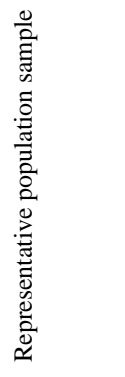 & $\begin{array}{l}\tilde{\Xi} \\
\text { dँ } \\
a \\
a\end{array}$ & 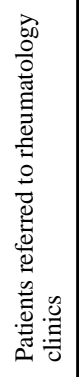 & 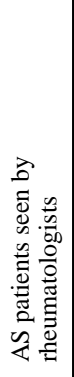 & 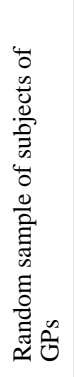 & 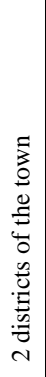 & 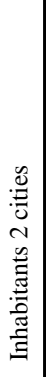 & 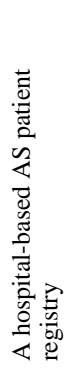 & 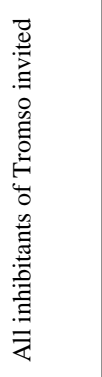 & 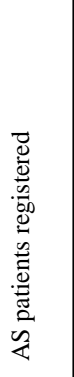 & 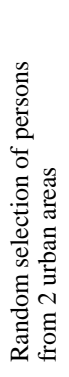 & 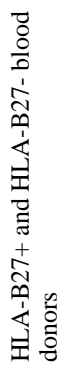 & 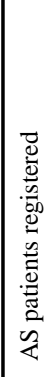 \\
\hline$\frac{8}{4}$ & $\frac{0}{\lambda}$ & $\frac{\infty}{\lambda}$ & $\stackrel{\curvearrowright}{\wedge}$ & $\stackrel{\infty}{\lambda}$ & $\frac{\theta}{\lambda}$ & $\frac{\infty}{\lambda}$ & $\frac{\infty}{\lambda}$ & $\underset{\wedge}{\stackrel{J}{A}}$ & $\begin{array}{l}\text { ț } \\
\text { 1े } \\
\text {. }\end{array}$ & $\frac{\circ}{\lambda}$ & 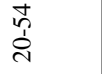 & $\frac{n}{\lambda}$ & $\stackrel{\sim}{\wedge}$ & & \\
\hline
\end{tabular}

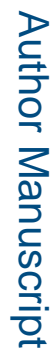

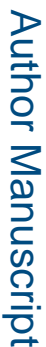

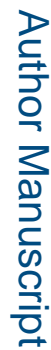

ำ

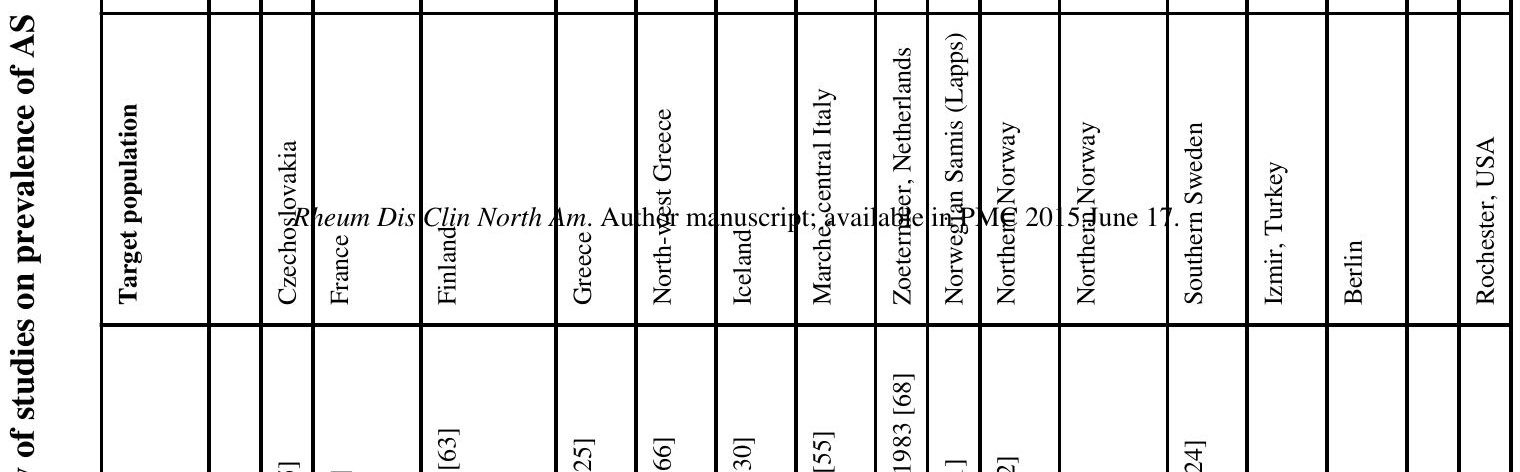




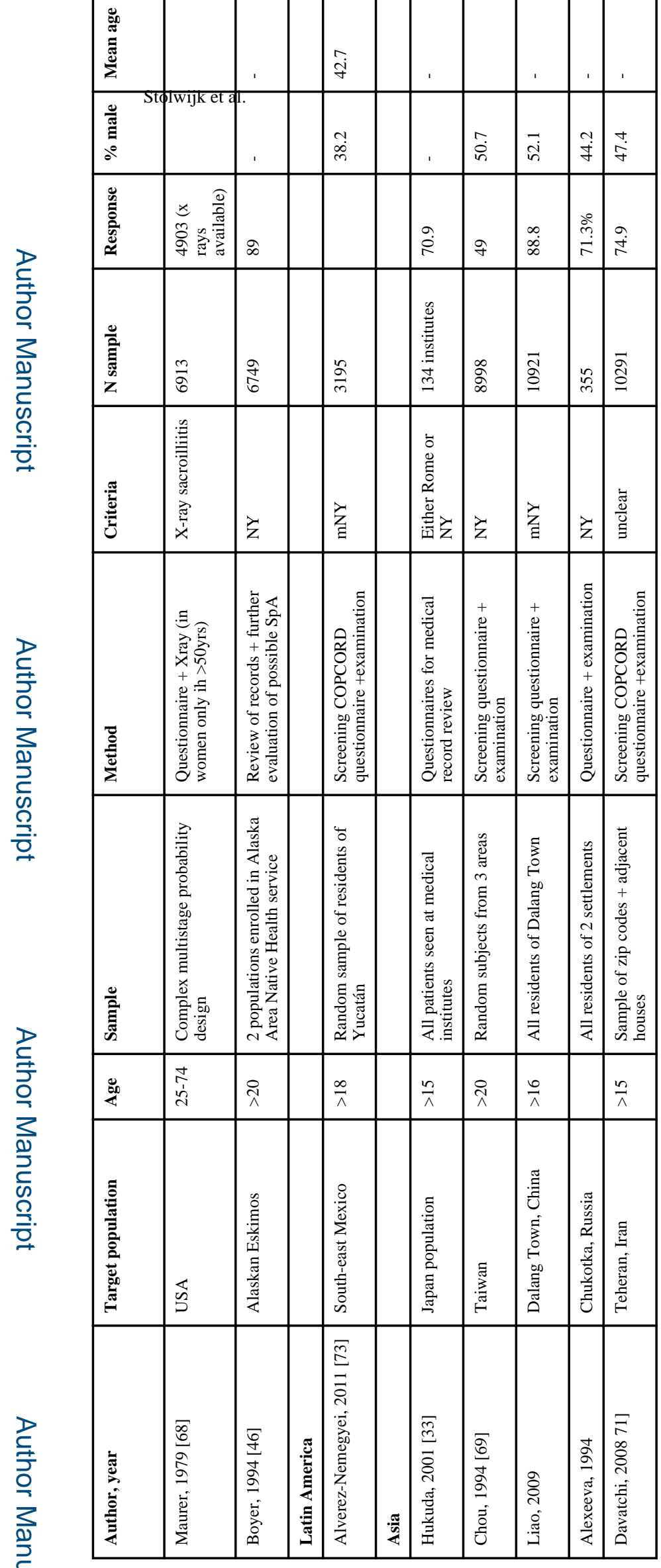

Page 30

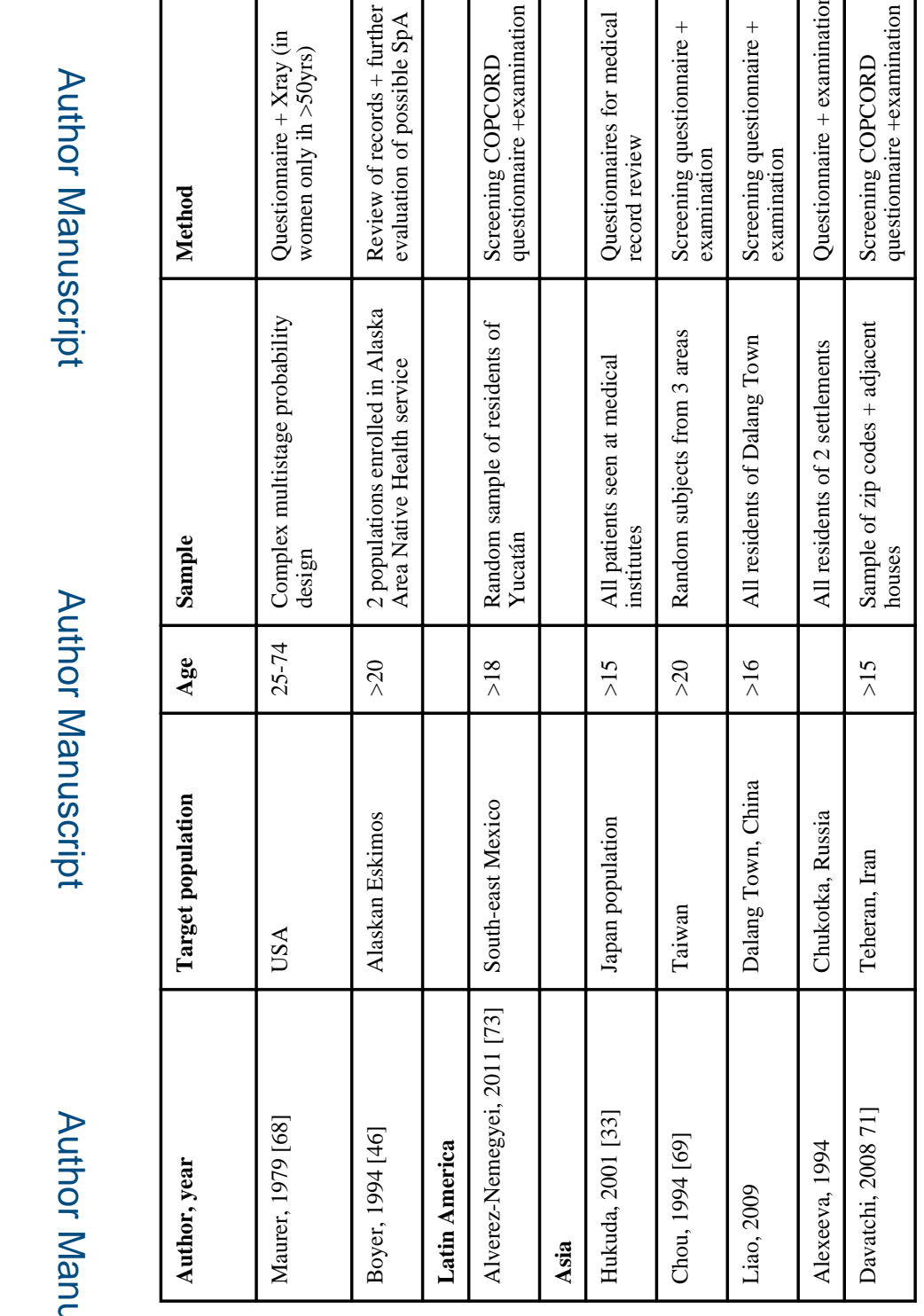

Rheum Dis Clin North Am. Author manuscript; available in PMC 2015 June 17. 


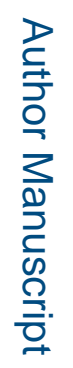

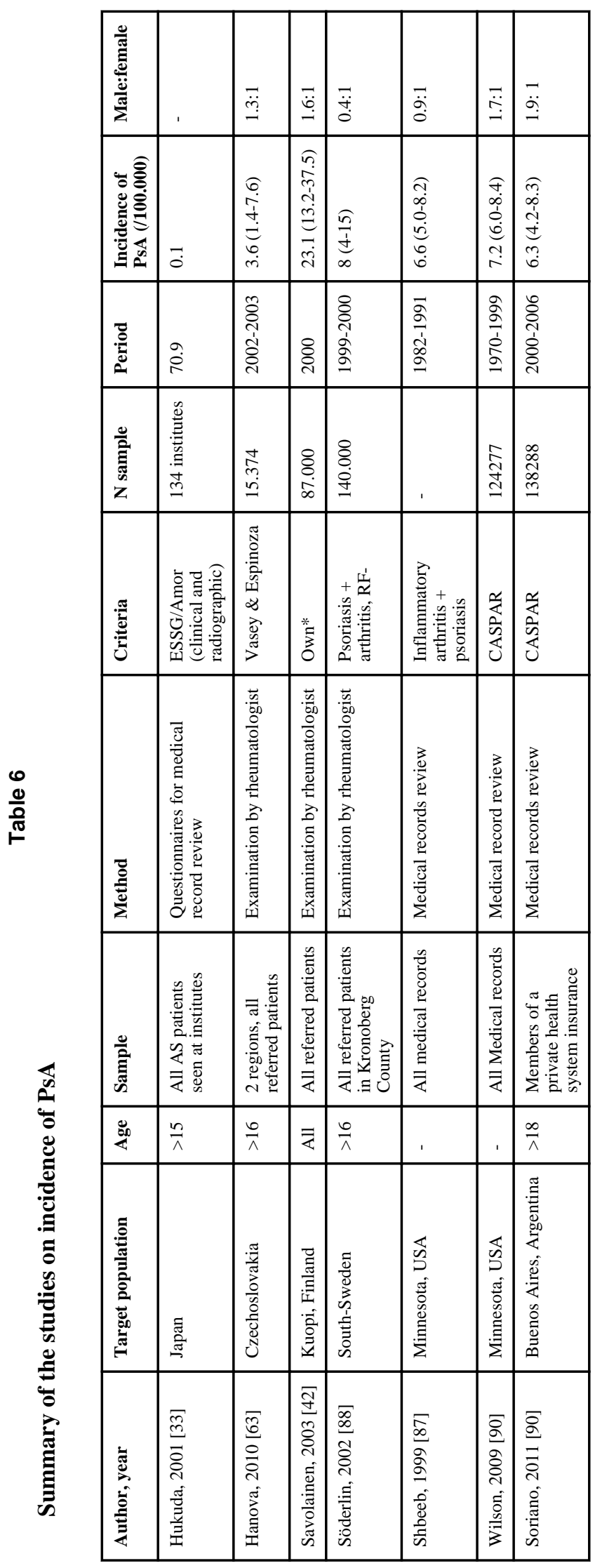

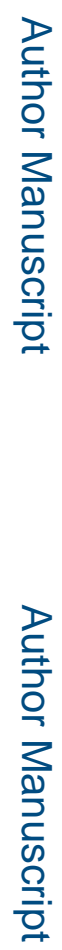

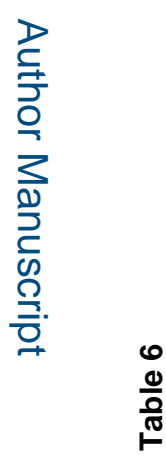

0
$\frac{0}{0}$
$\frac{0}{10}$

Rheum Dis Clin North Am. Author manuscript; available in PMC 2015 June 17. 


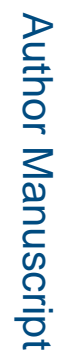

\begin{tabular}{|c|c|c|c|c|c|c|c|c|c|c|c|}
\hline 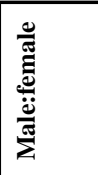 & $\begin{array}{l}\overline{\ddot{\alpha}} \\
\infty \\
\infty\end{array}$ & , & $\begin{array}{l}\overrightarrow{\ddot{o}} \\
\dot{+}\end{array}$ & , & 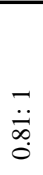 & & $\begin{array}{l}\vec{i} \\
i n \\
o\end{array}$ & ت્. & & $\ddot{\ddot{n}}$ & \\
\hline 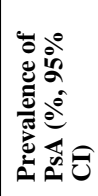 & $\begin{array}{l}0 \\
0 \\
0 \\
+1 \\
0 \\
0 \\
0 \\
0 \\
0\end{array}$ & 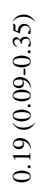 & $\begin{array}{l}\text { f } \\
\text { on } \\
0 \\
0 \\
0 \\
0 \\
\vdots \\
0 \\
0\end{array}$ & 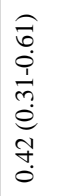 & 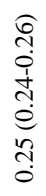 & ते & 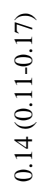 & 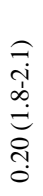 & $\begin{array}{l}a \\
\vdots \\
0 \\
d \\
0 \\
0 \\
0 \\
0\end{array}$ & $\begin{array}{l}\frac{\sigma}{0} \\
0 \\
\frac{1}{0} \\
0 \\
\stackrel{0}{0} \\
\frac{0}{0}\end{array}$ & $\overline{\dot{v}}$ \\
\hline 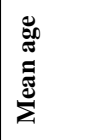 & , & , & f & , & , & $\begin{array}{l}n \\
\infty \\
\infty \\
m\end{array}$ & & & & & \\
\hline 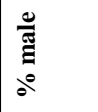 & , & , & $\begin{array}{l}\infty \\
\infty \\
\dot{\sigma}\end{array}$ & $\begin{array}{l}\text { o. } \\
\stackrel{+}{+}\end{array}$ & $g$ & $\hat{\sigma}$ & , & , & & , & ' \\
\hline 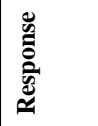 & , & 6 & $\stackrel{\sim}{\infty}$ & $\begin{array}{c}\infty \\
\stackrel{\infty}{\infty} \\
i\end{array}$ & , & 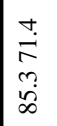 & . & . & & 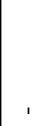 & के \\
\hline 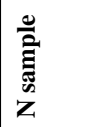 & 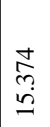 & 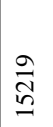 & 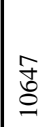 & 总 & 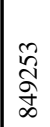 & $\stackrel{\infty}{\stackrel{\infty}{m}}$ & $\begin{array}{l}\text { ภे } \\
\text { ปे } \\
\text { }\end{array}$ & 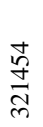 & & 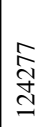 & 守 \\
\hline
\end{tabular}

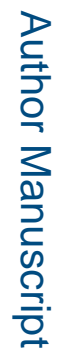

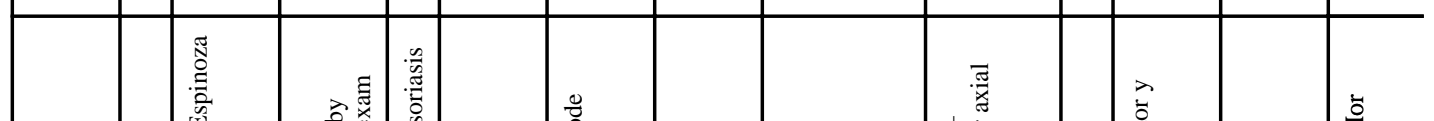

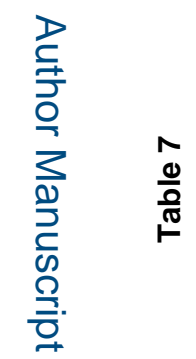

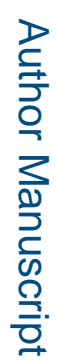

\begin{tabular}{|c|c|c|c|c|c|c|c|c|c|c|c|}
\hline نِّ & 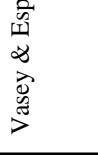 & 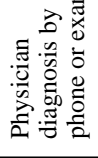 & 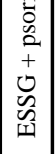 & 言 & $\begin{array}{l}\frac{0}{8} \\
0 \\
0 \\
10 \\
0\end{array}$ & $\begin{array}{l}\text { U } \\
\text { 心్ } \\
\text { In }\end{array}$ & 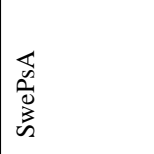 & 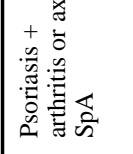 & 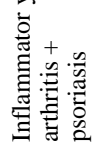 & $\begin{array}{l}\frac{\pi}{4} \\
\hat{\tilde{z}} \\
\text { Ù }\end{array}$ & 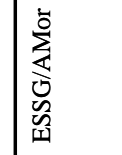 \\
\hline "ह & 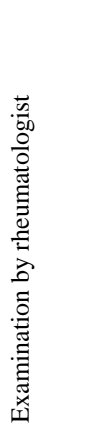 & 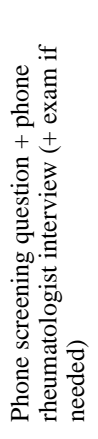 & 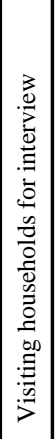 & 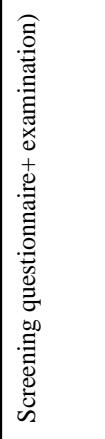 & 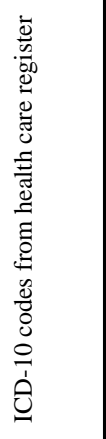 & 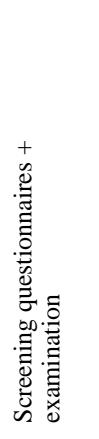 & 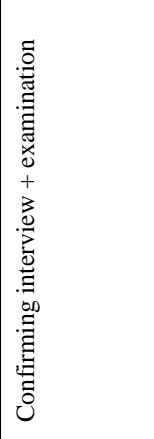 & 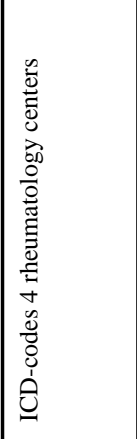 & 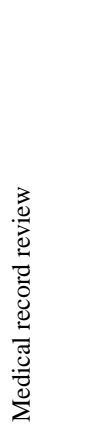 & 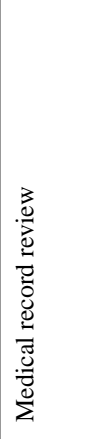 & 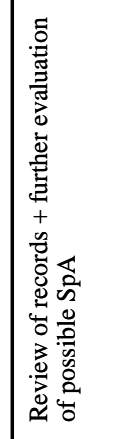 \\
\hline हू & 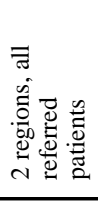 & 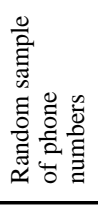 & 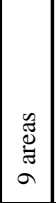 & 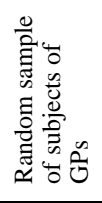 & 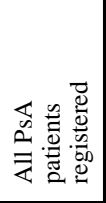 & 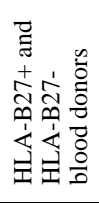 & 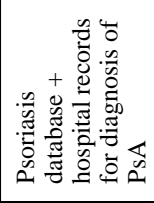 & 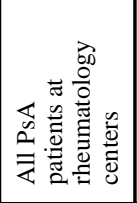 & 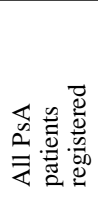 & 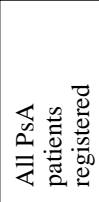 & 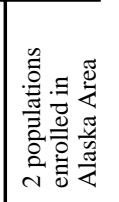 \\
\hline 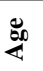 & $\frac{\circ}{\lambda}$ & $\frac{\infty}{\lambda}$ & $\underset{\wedge}{\stackrel{\infty}{\wedge}}$ & $\frac{\infty}{\lambda}$ & $\frac{n}{\lambda}$ & . & $\underset{\lambda}{\stackrel{\infty}{\lambda}}$ & त्रे & & & $\stackrel{\lambda}{\lambda}$ \\
\hline
\end{tabular}

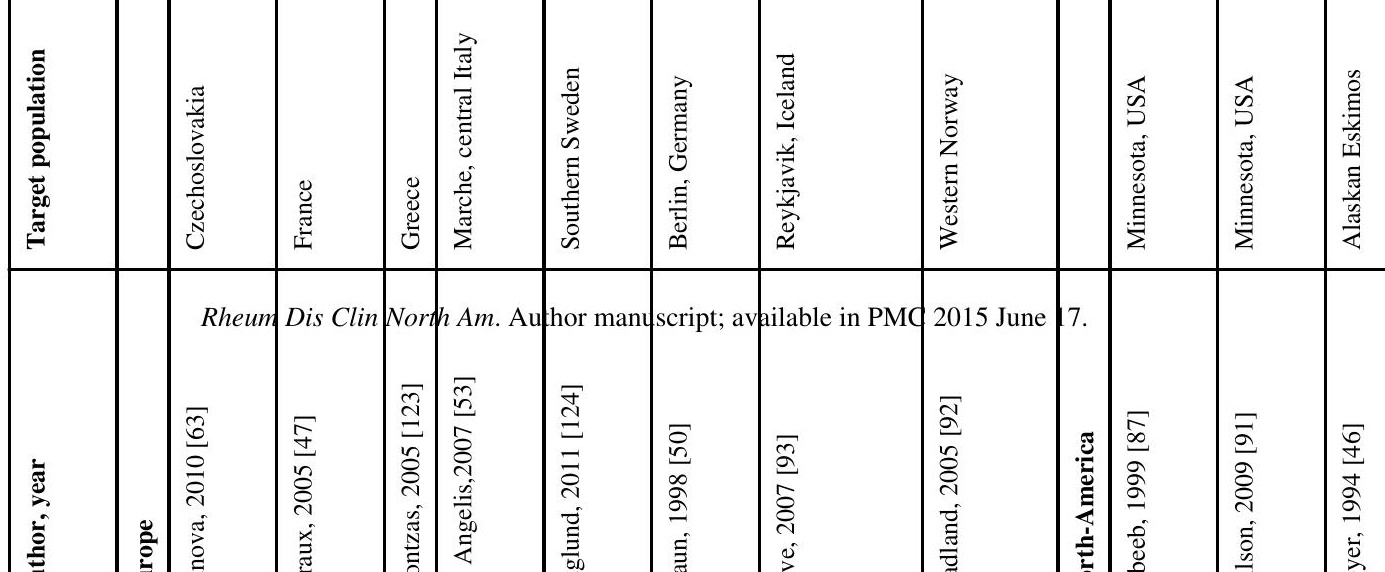




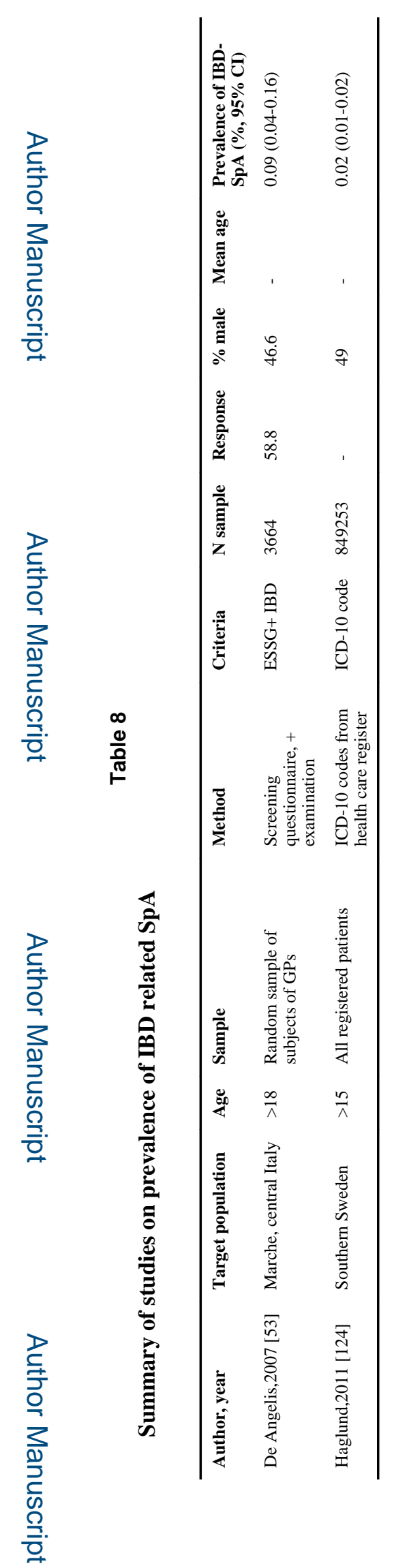

Rheum Dis Clin North Am. Author manuscript; available in PMC 2015 June 17. 


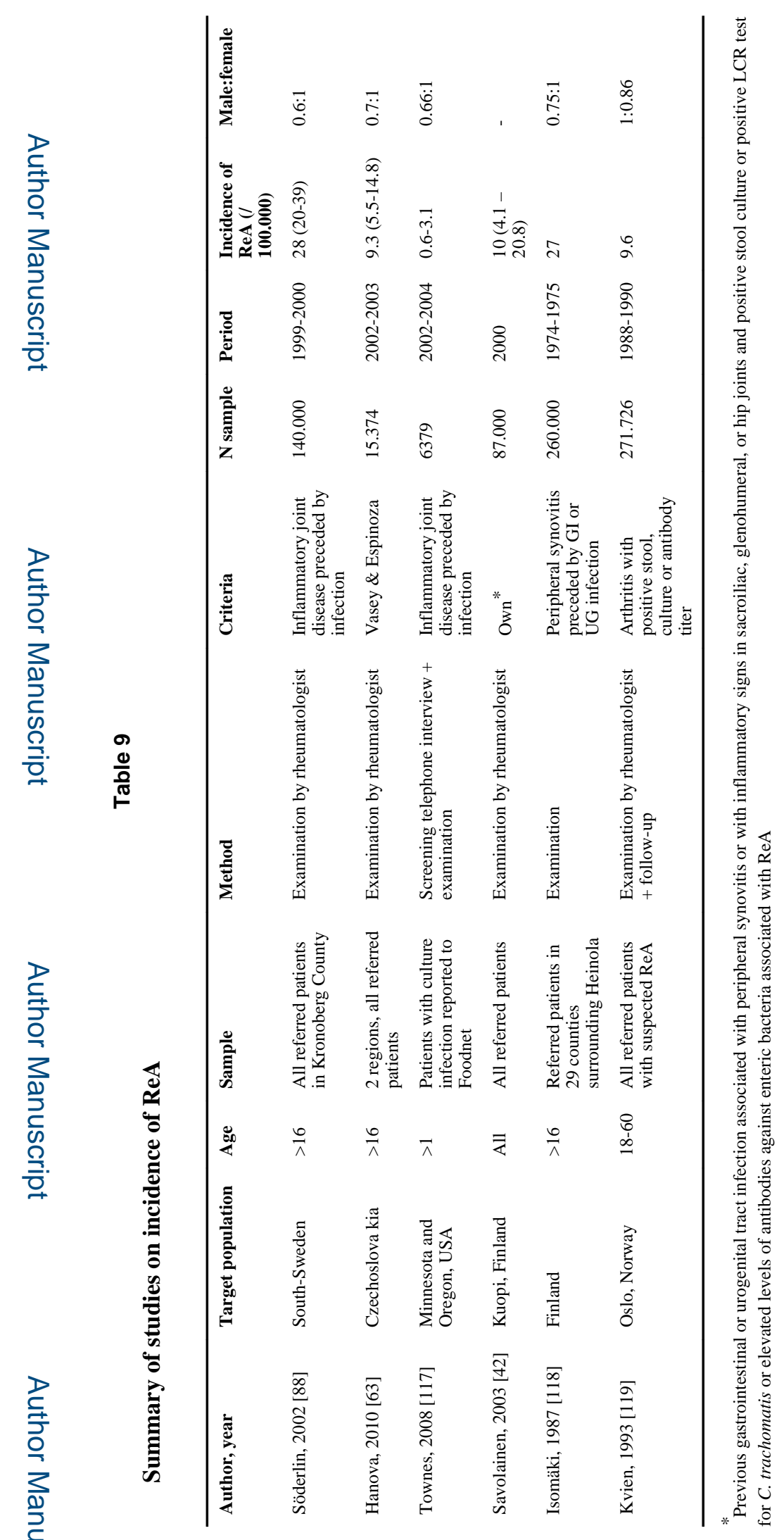

Rheum Dis Clin North Am. Author manuscript; available in PMC 2015 June 17. 


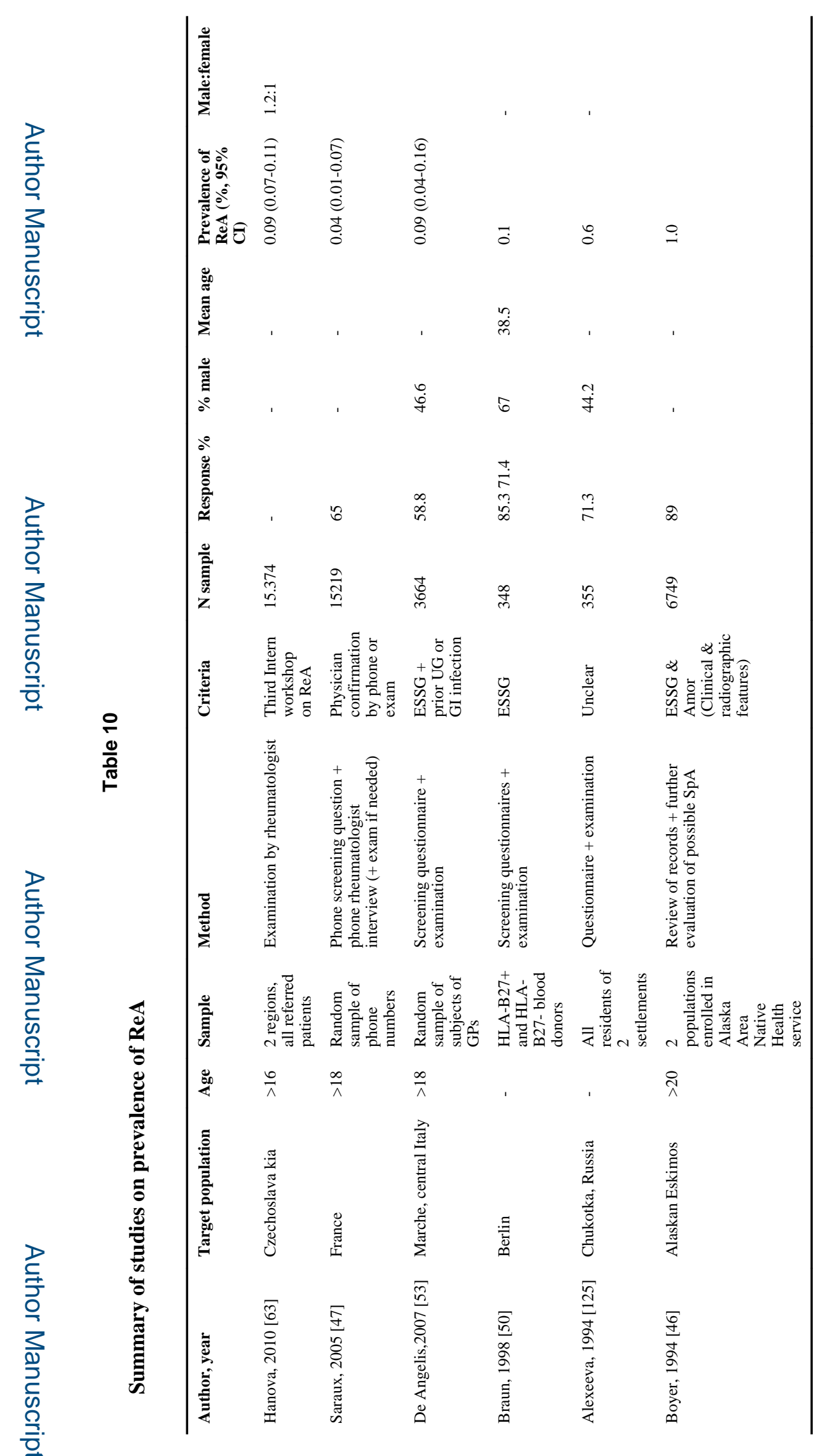

Rheum Dis Clin North Am. Author manuscript; available in PMC 2015 June 17. 